\title{
Procedures Based on Composite FEM Technology for the Resolution of Concrete-Framed Structures with Masonry In-Fills: Comparison with Mexican Building Code
}

\author{
Cuauhtemoc Escudero, Ph.D. ${ }^{1}$; Sergio Oller ${ }^{2}$; Xavier Martinez ${ }^{3}$; and Alex Barbat ${ }^{4}$
}

\begin{abstract}
The construction of confined masonry buildings has become a good choice to meet the housing needs of low-income families in big cities. Despite this, current building codes for such construction allow the use of highly simplified analysis techniques that have hardly changed in the last 40 years. This paper is based on numerical simulation and discusses the need to combine and improve existing techniques in finite-element method (FEM) analysis for composite materials, to assess the overall structural behavior of reinforced concrete structures with masonry in-fills, and consequently to support the derivation of rational rules for analysis and design. Through the use of a simple yet powerful shell finite element (FE), state-of-the-art theories of mixtures to analyze composite materials, a computational tool to generate the volume fraction of composites, and the Mexican building code, this paper attempts to be a guide to numerical reproduction of the overall behavior of confined masonry structures. DOI: 10.1061/(ASCE)EM.1943-7889.0001275. (C) 2017 American Society of Civil Engineers.
\end{abstract}

Author keywords: Laminated element; Composite materials; Large reinforced concrete (RC) structures; Mechanical plane; Masonry structures; Mexican building code.

\section{Introduction}

Confined masonry construction was introduced in Mexico City, Mexico, in the 1940s to control the wall cracking caused by large differential settlements under soft soil conditions. Several years later, this system became popular in other areas of highest seismic hazard because of its excellent earthquake performance (Meli and Alcocer 2004), but it was not until the early 1960s, when the proper study of confined masonry began, that Esteva (1961, 1963, 1966) tested masonry walls confined with reinforced concrete (RC). Several studies conducted at the time, such as Meli et al. (1968), Meli and Salgado (1969), Madinaveitia and Rodríguez (1970), Turkstra (1970), Meli and Reyes (1971), Madinaveitia (1971), and Meli and Hernández (1971, 1975), became the basis on which Hernández (1975) developed design and construction recommendations for structures made of masonry bearing walls. In 1977 the first Mexican code for design and construction of masonry structures was established, where, for design purposes, a simplified theory

${ }^{1}$ Departamento de Resistencia de Materiales y Estructuras en la Ingeniería, ETSECCPB, Technical Univ. of Catalonia, 08034 Barcelona, Spain (corresponding author). ORCID: https://orcid.org/0000-0001-6755 -0187. E-mail: cuauhtemoc@cimne.upc.edu; cescudero.ide@gmail.com

${ }^{2}$ Professor, Departamento de Resistencia de Materiales y Estructuras en la Ingeniería, ETSECCPB, Technical Univ. of Catalonia, 08034 Barcelona, Spain. E-mail: sergio.oller@upc.edu

${ }^{3}$ Professor, Departamento de Ciencia e Ingeniería Náutica, FBN, Technical Univ. of Catalonia, Pla de Palau 18, 08003 Barcelona, Spain. E-mail: xmartinez@cimne.upc.edu

${ }^{4}$ Professor, Departamento de Resistencia de Materiales y Estructuras en la Ingeniería, ETSECCPB, Technical Univ. of Catalonia, 08034 Barcelona, Spain. E-mail: alex.barbat@upc.edu

Note. This manuscript was submitted on July 11, 2016; approved on January 31, 2017; published online on May 31, 2017. Discussion period open until October 31, 2017; separate discussions must be submitted for individual papers. This paper is part of the Journal of Engineering Mechanics, (C) ASCE, ISSN 0733-9399. of the mechanical properties of materials was used, which led to models of confined masonry buildings subjected to ground shaking, where the walls serve

- As trusses (Brzev 2007): masonry walls act as diagonal struts subjected to compression, whereasRC confining members act in tension/compression, depending on lateral earthquake forces; and

- As frames (Fundación ICA 1999): confined masonry walls are modeled using an equivalent column, and it is assumed that the beams have infinite stiffness; diagonal struts are used to model the slabs.

In both cases, the analogies are highly simplistic and lack accuracy.

Research has also been extended to the numerical field and the application of the finite-element method (FEM). The majority of the strategies proposed for modeling the mechanical behavior of masonry were identified by Lourenço (1996) and Rots (1997) and can be classified in two categories, as explained in the following paragraphs.

In micromodeling, or two-phase material modeling, the components are considered separately to account for theirdifferent inelastic behavior and for the interaction between them. Analysis in this category is computationally quite expensive for several reasons, such as the great number of degrees of freedom (DOFs) involved, which require more input data, and their failure criterion, which has a complicated form because of the brick-mortar interaction. On the other hand, the constitutive equations of the components normally have a simple form, and they are suitable for the study of the local behavior of masonry. This modeling strategy is categorized as

- Detailed micromodeling, in which units and mortars are represented as a continuum, with the unit-mortar interfaces modeled using discontinuous interface elements as potential crack, slip, and crushing planes; and

- Simplified micromodeling, which adopts geometrically expanded masonry units with a single average interface representing the mortar and the two unit-mortar interfaces; this model 
requires the material model of the expanded unit and masonry joints.

In macromodeling, or one-phase material modeling, masonry is treated as an ideal homogeneous single material with constitutive laws that differ from those of the components (mortar and bricks). Constitutive models are more efficient for a practice-oriented analysis because of reduced calculation time and memory requirements and because of user-friendly mesh generation. The resulting material is regarded as an anisotropic composite, and a relation is established between average masonry strains and average masonry stresses. Such material must reproduce orthotropic behavior along with different tensile and compressive strengths along the material axes and different inelastic behavior for each material axis. This leads to more complicated constitutive equations.

Current theories that allow the use of two-dimensional (2D) FEs to model three-dimensional (3D) structures with composite yet powerful materials lack the necessary simplicity for application in complex structures, where a large number of FEs are required to obtain a good approximation of the result. Simpler and more efficient techniques are required for modeling 3D laminated structures.

The main objective of this work was to develop an efficient methodology to numerically reproduce the behavior of an entire masonry structure. This allows reliable analysis of the nonlinear response and so leads to full understanding of failure mechanisms and assessment of structural safety. To achieve this objective, stateof-the-art shell elements and mixture rules for composite materials were reviewed. Also, code regulations regarding the analysis and design of masonry buildings were roviewed and their resuits compared with the results from the prop the theoretical principles used were ble a robust numerical tool capable real-life structures from the linear gradation to complete loss of strength.

e paper is organized as follows. First an FE formulation for a shell finite element that reproduces in-plane (membrane) and outRegister to frepding nonlinear bepavior is briofly dgcribed; also materials. Next are described the methodology to determine the information related to simple and composite materials, the procedure to mechanically generate the volume fraction for composite materials, and the computational strategy followed in this work. Finally, a numerical test is presented and used to compare the methodology developed in this work with the Mexican national building code. The methodology aims to provide a general approach to analyze large-scale RC structures with masonry in-fills. The use of the Mexican code is merely to provide a basis for comparison of the obtained results in terms of initial stiffness and total shear strength.

\section{Finite-Element Formulation}

Simulation of large multilayered structures with many plies can be prohibitively expensive in three-dimensional analyses because of excessive computational cost, especially for nonlinear materials. In addition, the discretization of very thin layers can lead to highly distorted elements that cause numerical issues. Reduced models using multilayer shell elements have emerged as an affordable alternative (Eijo 2014).

This section briefly describes the shell element used in this work. Besides its reliability, this element was selected because of the manageable computational resources required for its implementation in a FE code.

\section{Shell Element Model}

One of the most popular approaches in the FE analysis of shells is to use an assemblage of flat triangular elements as an approximation of a curved surface, which can be obtained by combining a membrane and a plate bending element (Khosravi et al. 2007). There are several triangular plate bending elements to select and combine with membrane elements. The following subsection describes the elements selected for their reliability (Batoz 1982; Felippa 2003).

\section{Membrane Element}

A membrane element without an in-plane rotation degree (drilling rotation) causes in-plane rotation singularity (Hughes and Brezzi 1989). Successful attempts at developing membrane elements with drilling DOF were made by Allman (1984) and later Bergan and Felippa (1985), who developed an optimal membrane element (known as OPT) with drilling DOF. The DOFs of the OPT membrane element are collectable in the nodal displacement vector as

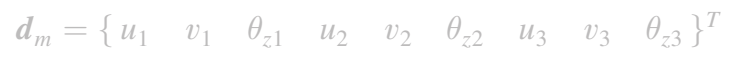

The fundamental element stiffness decomposition of the twostage direct fabrication method is

$$
\mathbf{K}_{m}=\mathbf{K}_{m b}+\mathbf{K}_{m h}
$$

where $\mathbf{K}_{m b}$ = basic stiffness, which takes care of consistency; and $\mathbb{K}_{m h}=$ high-order stiffness, which takes care of stability (rank suf-

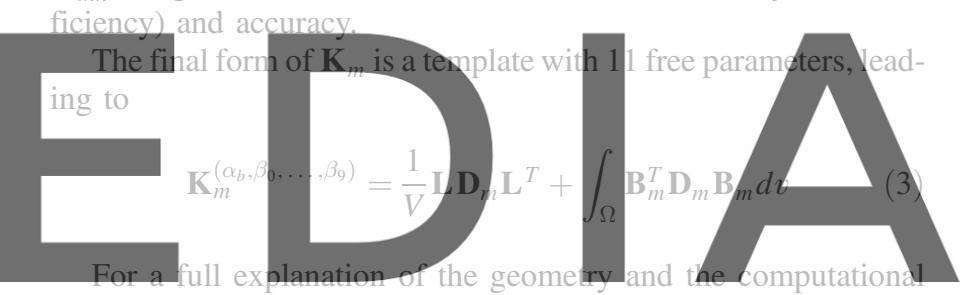

implementation of the OPT element, the reader may consult Felippa

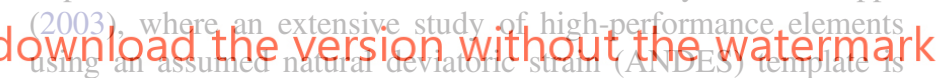
presented.

\section{Bending Element}

Batoz (1982) studied several triangular Kirchhoff plate bending elements and showed that the discrete Kirchhoff triangle (DKT) (Batoz et al. 1980) is the most reliable triangular element for the analysis of thin plates. The DOF for such an element can be presented in a vector as

$$
\boldsymbol{d}_{b}=\left\{\begin{array}{lllllllll}
w_{1} & \theta_{x 1} & \theta_{y 1} & w_{1} & \theta_{x 2} & \theta_{y 2} & w_{1} & \theta_{x 3} & \theta_{y 3}
\end{array}\right\}^{T}
$$

Here the evaluation of the stiffness matrix follows standard FEM procedures:

$$
\mathbf{K}_{b}=\int_{\Omega} \mathbf{B}_{b}^{T} \mathbf{D}_{b} \mathbf{B}_{b} d A=2 A \int_{0}^{1} \int_{0}^{1-\zeta_{3}} \mathbf{B}_{b}^{T} \mathbf{D}_{b} \mathbf{B}_{b} d \zeta_{2} d \zeta_{3}
$$

For a full description of the DKT element and its numeric implementation, the reader may consult Batoz et al. (1980).

In this work, the DKT element was combined with the plate element enhancement proposed by Escudero (2015) and Escudero et al. (2016), where for the integration along the element thickness an equivalent single layer (ESL) description is used which takes into account the evolution of the eccentricity of geometric and mechanical planes, making it suitable for modeling the bending damage of shell structures at a low computational cost because there is no need of DOFs other than the ones given in Eq. (4). 


\section{Constitutive Formulation}

This section briefly describes the expected bending degradation, focusing on the evaluation of the secant constitutive tensor $\mathbf{D}^{\text {sec }}$, which is required to reproduce the bending degradation that arises when some layers within a laminated plate are beyond the elastic threshold and others are not.

\section{Concrete}

Concrete is a composite material made up of a granular material (aggregate) embedded in a hard matrix (cement). It is common practice to represent concrete behavior using a macromodel scheme for a simple quasi-brittle geomaterial, even though its high nonlinear performance is achieved because of the formation of microcracks and slipping among its aggregate particles (Oller 1998). There is much interest in the mechanical properties of concrete because of its wide application in the construction field, and several researchers have developed constitutive models to represent its mechanical behavior (Bazant and Pijaudier-Cabot 1989: Hillerborg et al. 1976; Rots and De Borst 1987). However. it was not until the early 1980s that models based on continuum damage mechanics (CDM) were applied to the modeling of concrete materials (Chaboche 1988a, b; Ju 1989; Lemaitre 1985; Oliver et al. 1990; Simo and Jul 1987, 1989).

Two-Scalar Damage Models. Among the possibilities that CDM offers are isotropic damage models, where nonlinear behavior is monitored through a single internal scalar damage (or degradation) variable $d$, which measures the loss of stiffness in the material in the range of 0 to 1 , where 0 is undamaged and 1 is fully degraded (Olivey et al. 1990). Another approach to modeling the opening and closing of cracks due cyclic loads in geomaterials thas proposed by Faria et al. (1998), where iables $d^{+}$and $d^{-}$distinguish betw tensile stresses (cracking) and the esses (crushing). This scheme is more convenient for seisThe definition of the elastic secant constitutive tensor is as folRegister rfforir free at' https//www.scipedia.com to

$$
\mathbb{D}^{\mathrm{sec}}=\frac{\partial \sigma}{\partial \boldsymbol{\varepsilon}}=\left(1-d^{+}\right) \frac{\partial^{2} \Psi_{0}^{+}}{\partial \varepsilon^{e} \otimes \partial \varepsilon^{e}}+\left(1-d^{-}\right) \frac{\partial^{2} \Psi_{0}^{-}}{\partial \varepsilon^{e} \otimes \partial \varepsilon^{e}}
$$

where

$$
\boldsymbol{\sigma}=\mathbf{D}^{\mathrm{sec}}: \boldsymbol{\varepsilon}
$$

The use of two internal variables to reproduce damage is an advantage in terms of constitutive analysis. However, it becomes cumbersome when trying to establish a single parameter that defines the material degradation. This can only be achieved with an equivalent damage index (Paredes et al. 2011) [Eq. (13)].

In this work, the damage model representing the behavior of geomaterials was based on the scheme developed by Paredes (2013), which was conceptually based on the scheme proposed by Faria et al. (1998) in that it consists of a two-scalar damage model.

\section{Masonry}

Depending on the accuracy and the simplicity desired, masonry can be modeled in the following ways:

- Detailed micromodeling: units and mortar in the joints are represented by continuum elements, whereas the unit-mortar interface is represented by discontinuous elements;

- Simplified micromodeling: expanded units are represented by continuum elements, whereas the behavior of the mortar joints and unit-mortar interface is lumped in discontinuous elements;
- Macromodeling: units, mortar, and the unit-mortar interface are bonded in the continuum; and

- Homogenized modeling: this strategy is midway between micromodeling and macromodeling because it consists of obtaining macroconstitutive laws starting from the microconstitutive law of the constituents and the internal geometry of the masonry. Advantages and disadvantages of each approach are discussed in Lourenço et al. (2007), Lourenço (1996), and Pelà (2009). Here a macromodeling approach, combining the damage model proposed by Paredes (2013) with the orthotropic yield criterion proposed by Oller et al. (2003), is used. This scheme is more practice oriented because of its reduced time and memory requirements and its implied user-friendly mesh generation. Also, it provides the best compromise between accuracy and efficiency.

Orthotropic Yield Criterion. The objective of the approach proposed by Oller et al. (2003) is to adjust an arbitrary isotropic yield criterion to the behavior of an anisotropic material. It is very convenient to apply this scheme to a macromodeled masonry material because of the material's anisotropic nature.

The transformed-tensor method is based on assuming the existence of a real anisotropic space of stresses $\sigma_{i j}$ and a conjugate space of strains $\boldsymbol{\varepsilon}_{i j}$, such that each of these spaces has its respective image in a fictitious isotropic space of stresses $\bar{\sigma}_{i j}$ and strains $\overline{\boldsymbol{\varepsilon}}_{i j}$, respectively. The corresponding relationships among them are

$$
\bar{\sigma}_{i j} \stackrel{\text { def }}{=} A_{i j k l}^{\sigma} \sigma_{k l} ; \quad \bar{\varepsilon} \stackrel{\text { def }}{=} A_{i j k l}^{\varepsilon} \boldsymbol{\varepsilon}_{k l}
$$

Here $A_{i j k l}^{\sigma}$ and $A_{i j k l}^{\varepsilon}$ are the transformation tensors for stress and

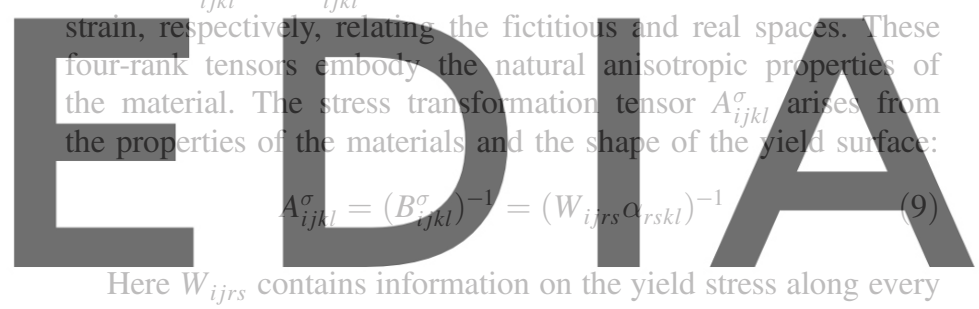

axis of orthotropy and $\alpha_{r . k}$ is the shape adjustment tensor (Oller dowahload sthienversho miwithoubt the weatermark strain transformation tensors can therefore be expressed as

$$
A_{r s m n}^{\varepsilon}=\left[\bar{C}_{r s i j}^{\sigma}\right]^{-1} A_{i j k l}^{\sigma} C_{k l m n}^{\sigma}
$$

where $\bar{C}_{r s i j}^{\sigma}$ and $C_{k l m n}^{\sigma}=$ constitutive tensors in the fictitious space and the real space, respectively.

Steel. The most common approach to representing the behavior of ductile materials, such as steel, is via a macromechanical theory of plasticity (Kojić and Bathe 2005) based on the notion of a yield surface giving the yield condition, a hardening rule, and on the stress-plastic strain relations of the given material.

The concepts of classic plasticity can be extended to plastic damage models like the one proposed by Oller (1998) or by Martinez et al. (2015), where plasticity is modeled using a normalized internal variable to represent plastic damage $\kappa^{p}$. The range of values for $\kappa^{p}$ is $0 \leq \kappa^{p} \leq 1$, where $\kappa^{p}=0$ indicates no plastic damage and $\kappa^{p}=1$ indicates total damage of a solid.

There are other CDM schemes that include the effect of permanent deformations on the mechanical behavior of geomaterials (Jason et al. 2006; Lubliner et al. 1989; Mazars and PijaudierCabot 1989; Tao and Phillips 2005), especially in concrete subjected to compression, where the internal variables are represented by damage variables. Also included is permanent plastic deformation.

The idea of using a single damage variable in a general form was explored by Paredes (2013) as applied to assessment of the natural vibration frequency of structures. Paredes considered the 
possibilities for defining the damage index $d$ and proposed the in$\operatorname{dex} d^{\text {eqv }}$ as a function of yield surface $f\left(\boldsymbol{\sigma}_{0}\right)$ defined as

$$
d^{\mathrm{eqv}}=1-\frac{f\left(\boldsymbol{\sigma}_{0}^{c}\right)}{f\left(\boldsymbol{\sigma}_{0}\right)}
$$

Thus it is now possible to use the damage index $d^{\text {eqv }}$ from Eq. (7) to obtain an equivalent secant tensor. In Eq. (11) $f\left(\boldsymbol{\sigma}_{0}\right)$ is evaluated with the current tensor of stress, whereas $f\left(\boldsymbol{\sigma}_{0}^{c}\right)$ is evaluated with the tensor of effective stresses that define the damage threshold of the material:

$$
\boldsymbol{\sigma}_{0}^{c}=\left[\begin{array}{ccc}
f_{0}^{*} & 0 & 0 \\
0 & 0 & 0 \\
0 & 0 & 0
\end{array}\right]
$$

where $f_{0}^{*}=$ nominal threshold of the material's resistance.

For concrete, this threshold is defined by resistance to compression; for ductile materials such as steel, it is defined by yield stress.

Finally $\mathrm{Eq}$. (11) incornorates the modification of $\mathrm{Eq}$. (7), resulting in Eq. (13):

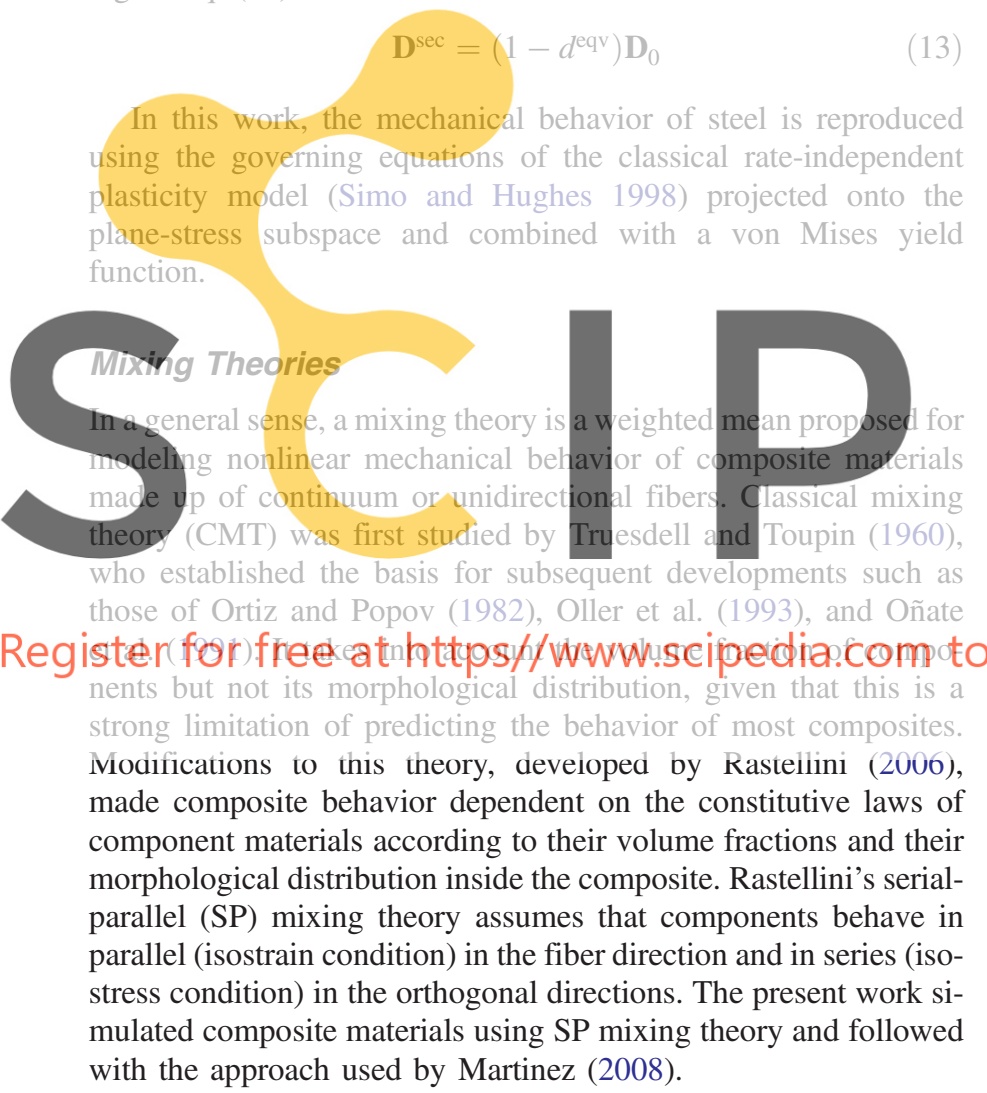

\section{Proposed Methodology}

From a computational-cost point of view, the only viable strategy for the analysis of structures formed by a large number of masonry units and joints, and confined by RC elements with different reinforcement patterns, is the use of a smeared-cracking law and macromodeling. Hence the present section focuses on the information required for a proper description of composite materials. It also focuses on the meshing requirements of the analysis of such structures. An initial concern in the proposed scheme was that the computational cost, in terms of time and random access memory (RAM), would be rather high. To overcome this disadvantage, some alternatives were explored as explained in the following sections.

\section{Thickness Discretization for Structural Elements}

The shell element model used in this work reproduced out-of-plane degradation due to bending stresses. To achieve high accuracy, it was mandatory to perform a finer layer distribution of the laminated materials in the following cases (Escudero 2015):

- At the zones furthest away from the geometric axis of the shell because such layers are subjected to higher stresses during a bending moment; and

- At zones where an abrupt change in stiffness exists, as with steel reinforcement in concrete, no matter their position in the overall thickness.

\section{Meshing and Composite Materials Generation}

To cover the meshing, a pre- and postprocessor was required, in this case GiD (CIMNE 2015), a universal, adaptive, and user-friendly software used in science and engineering. GiD is designed to cover all common needs in numerical simulation, such as pre- and postprocessing, geometrical modeling, effective definition of analysis data, meshing, data transfer to analysis software, and visualization of numerical results. Obtaining the required information to model a large structure formed by laminated materials, where each layer is a composite, can be a cumbersome task. This is because, within the laminated material, not only fiber orientation but also layer thickness can change, leading to changes in the volume participation of the fiber and matrix. To overcome this situation, and to reproduce real-life structures in terms of steel reinforcement patterns (SRPs), a computational tool was developed with the following requirements

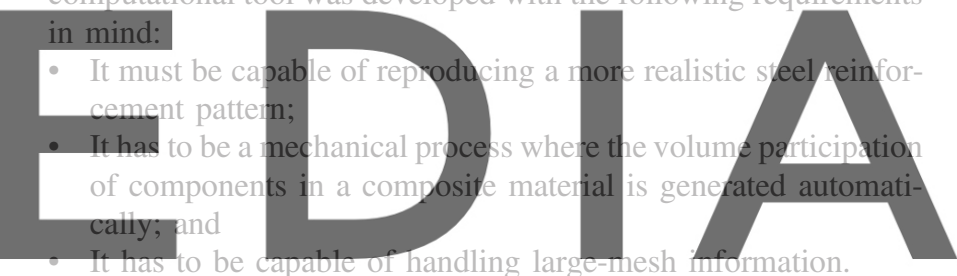

Such a tool is necessary for mechanizing and generating infor-

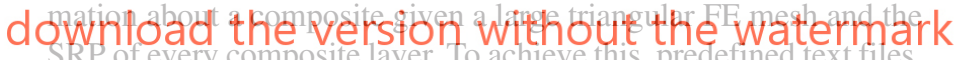
where the SRP information is stored, are used

The starting point of this task is the structured composite material (SCM), where a pattern is selected to represent both the reinforcement steel in the layers and the SCM's boundary. The main idea is to make the generation of the composite material for every layer of the FE as mechanical as possible.

Readers familiar with computer-aided design software, will find similarities to it in the SCM hatch. Both programs involve pregenerated patterns of bidimensional closed polygons (steel reinforcement in the case of a SCM) stored in a text file and ready for use as needed. The file contains information such as contour, local $x^{\prime}-$, $y^{\prime}$-plane, and an insertion point. The code generates information such as volume participation, fiber direction (when applicable), and SCM layer thickness. The steps to generate such information are follows:

1. The text file containing information related to all SCMs in the model is generated; it also contains information boundaries and insertion points;

2. The FE mesh is generated for the model (using GiD);

3. The code searches for the FEs intersecting the contour of the SCM;

4. The code evaluates the volume participation of the matrix ${ }^{m} k$ and fiber ${ }^{f} k$ for each layer using the intersecting area of the $\mathrm{SRP}$ with the FE; if the layers have no steel reinforcement ${ }^{f} k=0$, classic mixing theory applies; if ${ }^{f} k \neq 0$, serial-parallel mixing theory applies; and 

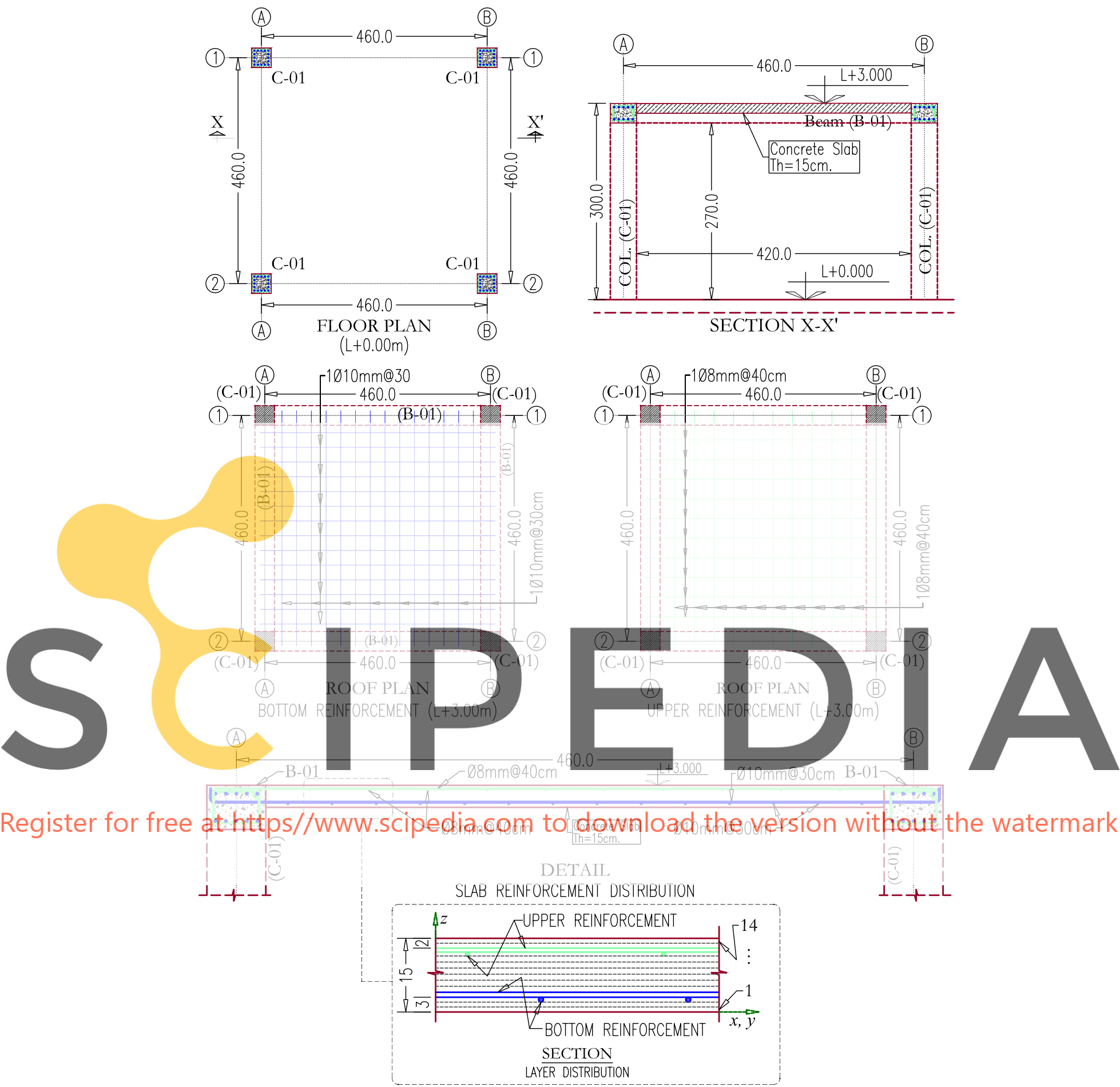

Fig. 1. Structural drawings (plans and elevations) of a typical framing construction

5. The code smoothes the volume participation of the fiber to reduce the number of composite materials.

Fig. 1 shows the proposed method in structural drawings of a building with columns of Type C-01 and beams of Type B-01; it also shows the distribution of the steel reinforcement for the concrete slab. Using the proposed scheme to model the structure in Fig. 1 requires a total of three SCMs. The first one (SCM-01) represents the frame of Axes 1 and 2; the second one (SCM-02) represents only the beams along Axes $\mathrm{A}$ and $\mathrm{B}$; and the third one (SCM-03) represents the concrete slab. Section $\mathrm{X}-\mathrm{X}^{\prime}$ in Fig. 1 can be seen as SCM-01 because it can be repeated over Axes 1 and 2 .

Using Fig. 2 as a reference, the first step is to generate the SCM information, using as the starting point the discretization along the cross section of the corresponding structural elements [Fig. 2(a)], to later define the contour and an insertion point A to which the reinforcement pattern of all layers refer [Fig. 2(d)]. The second step is generating the mesh, and the third step is searching for the FEs that intersect the contour of the SCM as shown in Fig. 2(c) (SCM01 at Axis 2). The fourth step overlaps the reinforcement pattern 

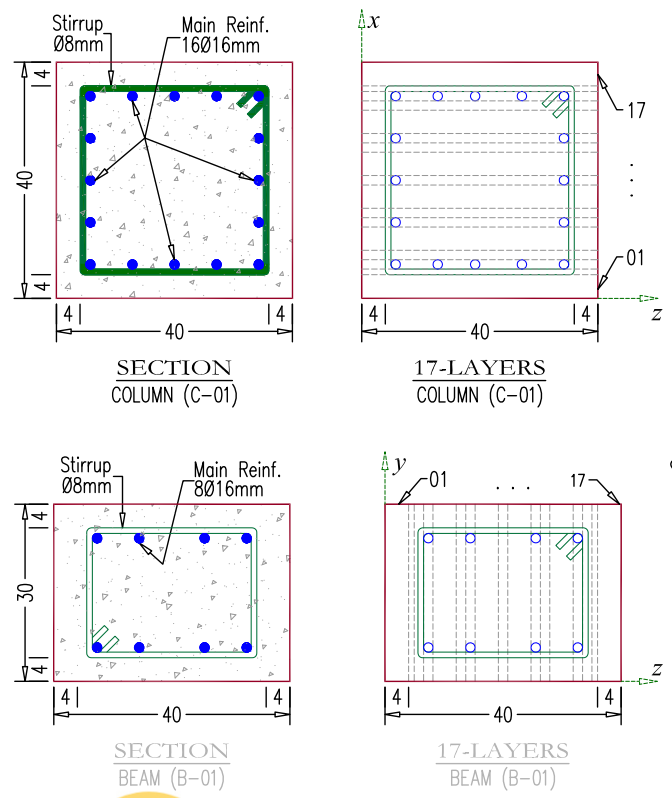

(a)
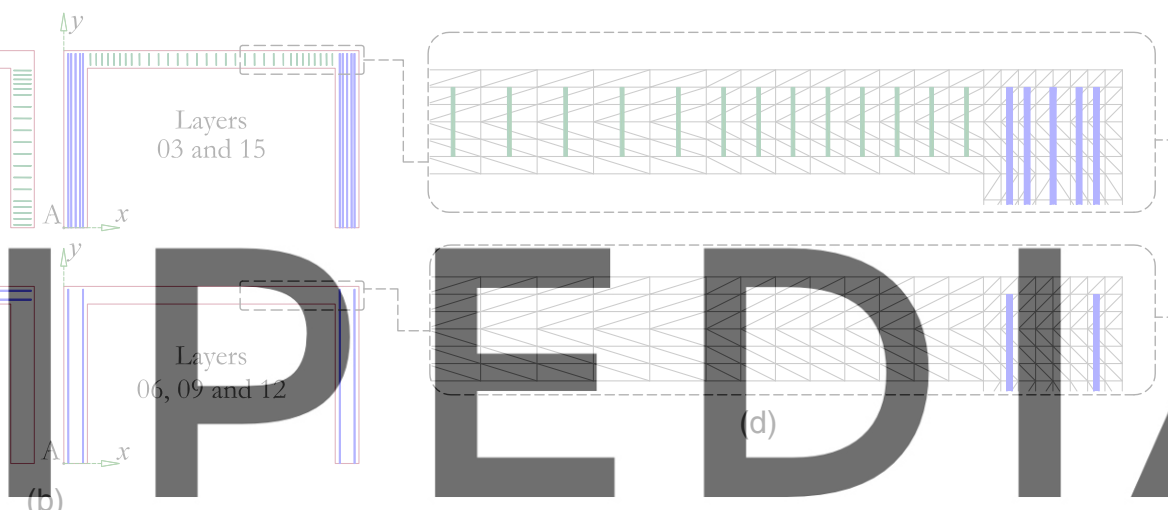

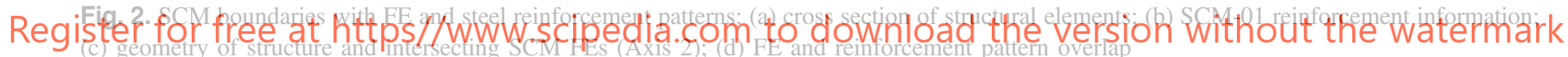

and the intersecting FEs of a given SCM to obtain the volume participation of the matrix ${ }^{m} k$ and fiber ${ }^{f} k$ and the fiber direction for each layer [Fig. 2(d)]. The fifth step reduces the amount of composite materials generated in the process.

\section{Computational Strategy}

This section describes the improvements made in PLCd (CIMNE 2014) that make possible analysis of large structures in a reasonable amount of time. Written in FORTRAN, PLCd is a state-of-the-art implicit FE code originally developed by Professor Oller, at the International Center for Numerical Methods in Engineering in Barcelona, to treat a large variety of composite materials using the rules of mixtures.

\section{Time-Based Optimization}

The optimization process in terms of time is carried out using a parallelization scheme with OpenMP (Barney et al. 2010) directives in three sections of the code:

- Loop over elements while evaluating the generalized strains $\hat{\boldsymbol{\varepsilon}}$ and the generalized stresses $\hat{\boldsymbol{\sigma}}$;

- Loop over elements while integrating the constitutive equations (plasticity, damage, etc.) with the goal of evaluating the internal forces of each FE so they can be assembled into a global vector usually referred to as $\mathbf{L} \mathbf{H S}$; elemental $\mathbf{L} \mathbf{H S} \mathbf{S}_{e}$ can be evaluated in different threads and later assembled, restricting access to $\mathbf{L} \mathbf{H S}$ to only one thread at the time; and

- Loop over elements while writing/reading information to perform a restart operation.

\section{Memory Consumption Optimization}

A scheme employing user-defined data types was implemented, where, at the beginning of the analysis process, the information is reserved and allocated only when needed (once the FE is in a nonlinear range), leading to lower RAM memory requirements. Starting from the assumption that not all elements reach nonlinear behavior, the proposed programming scheme was implemented in PLCd in the following ways:

- To serve as a template to store internal variables for every nondamaged FE with the same composite information; at this point, it is not necessary to store composite strain or stress or laminated material components;

- Once a component in a FE is behaving nonlinearly, memory to store information on the FE is required (internal variables, stresses, and strains);

- Memory is allocated at every loading step or iteration, which is time consuming; however, this is a minor drawback in the 
analysis of large structures, where a considerable amount of RAM is required; and

- For output and visualization (writing information in GiD format), nondamaged FE information is evaluated using local displacements, which can be seen as the major drawback of this scheme.

Basically, if any components in any layer of the laminated material reach a nonlinear range, the FE is considered damaged, requiring information about the components to be stored. Otherwise, strains and stresses are evaluated using local FE displacements.

To reduce RAM requirements, an iterative solver was added to PLCd using the library developed by Vargas and Botello-Rionda (2012). This library contains routines running in parallel to solve typical linear systems of equations resulting from finite-element or finite-volume discretizations with a large number of unknowns. In the studied cases, only comparisons in terms of consumed memory were carried out; however, further comparisons in terms of running time would be required to fit the best alternative.

\section{Numerical Examples}

This section describes two practical examples intended to test the capabilities of the proposed analysis scheme. The first one is an experimental test carried out by Meli (1979) to reproduce, from an experimental point of view, the isolated behavior of a masonry wall confined by two columns and a beam made of reinforced con-

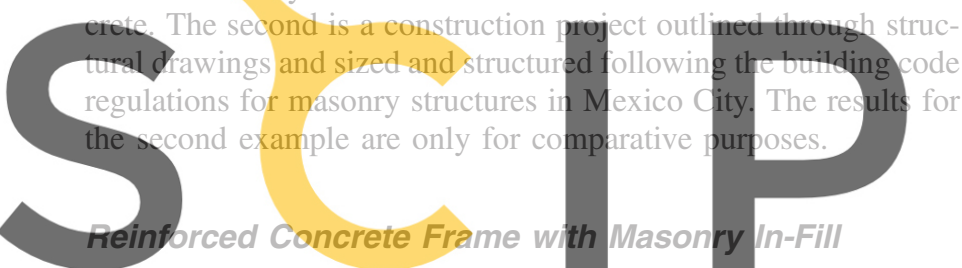

The example in this section involves an experimental test carried out by and fully described in Meli (1979). The geometry of the

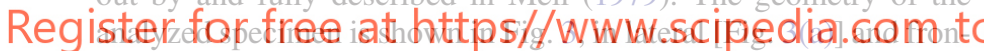
tal [Fig. 3(b)] views; also shown are the location of the confining structural elements (C-01 and B-01), the distribution of the masonry units, and the boundary conditions (an imposed displacement at the top and a fixed support at the bottom), along with the

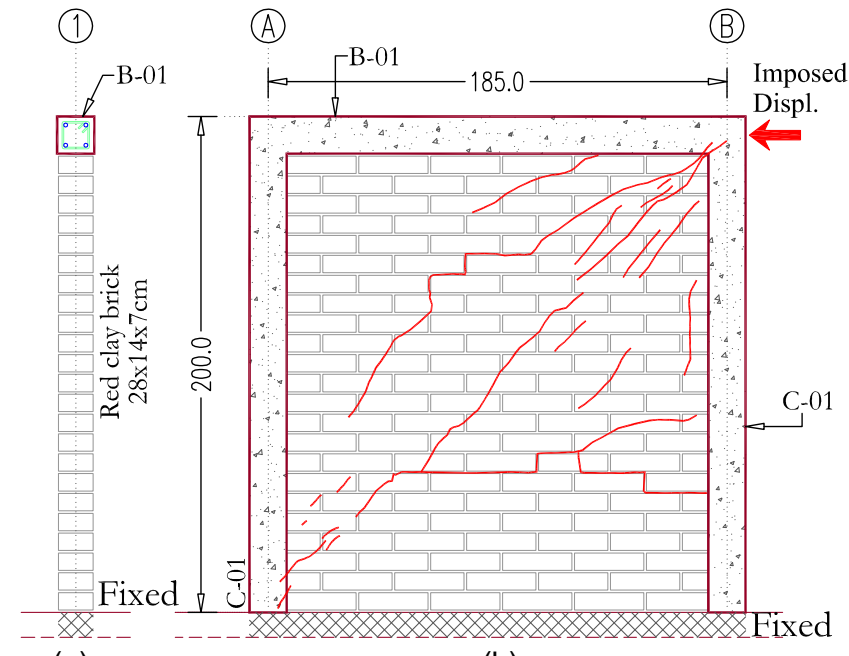

(a)

(b)

Fig. 3. Geometry, crack patterns, loading, and boundary conditions for cantilever wall with masonry in-fill overlapping of the crack patterns from the test [Fig. 3(b)]. In the present study, the masonry in-fill exhibited the typical response seen in low-resistance masonry units: cracks crossing indistinctly throughout the masonry unit or mortar.

To numerically reproduce the present model, three simple materials were required, whose mechanical properties are described next.

\section{Steel}

The mechanical properties of steel are described in Eq. (14):

$$
\begin{aligned}
E & =2.1 \times 10^{5} \mathrm{MPa} \\
v & =0.00 \\
\gamma & =7845 \mathrm{~kg} / \mathrm{m}^{3} \\
\sigma_{c} & =270 \mathrm{MPa} \\
\sigma_{t} & =270 \mathrm{MPa} \\
G_{c} & =2.0 \mathrm{MPa} \cdot \mathrm{m} \\
G_{t} & =2.0 \mathrm{MPa} \cdot \mathrm{m}
\end{aligned}
$$

where $E=$ elasticity modulus; $v=$ Poissons's ratio; $\gamma=$ self-weight; $\sigma_{c}$ and $\sigma_{t}=$ damage thresholds for compressive and tensile stresses, respectively; and $G_{c}$ and $G_{t}=$ fracture energy in, respectively, compression and tension using a von Mises yield criterion

\section{Concrete}

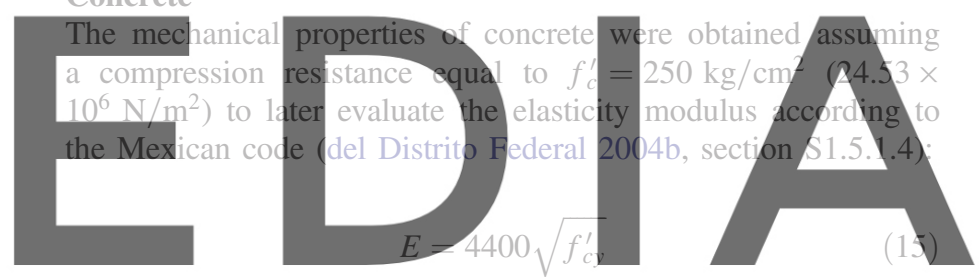

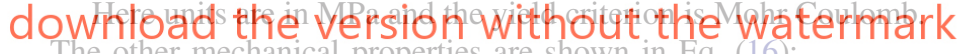 \\ The other mechanical properties are shown in Eq. (16):}

$$
\begin{aligned}
E & =2.18 \times 10^{4} \mathrm{MPa} \\
v & =0.20 \\
\gamma & =2.500 \mathrm{~kg} / \mathrm{m}^{3} \\
\sigma_{c} & =24.53 \mathrm{MPa} \\
\sigma_{t} & =2.45 \mathrm{MPa} \\
G_{c} & =50.0 \mathrm{kPa} \cdot \mathrm{m} \\
G_{t} & =5.0 \mathrm{kPa} \cdot \mathrm{m}
\end{aligned}
$$

\section{Masonry}

The mechanical properties of the masonry in-fill were obtained assuming compression resistance of $f_{m}^{\prime}=40 \mathrm{~kg} / \mathrm{cm}^{2}(3.92 \mathrm{MPa})$ and $v_{m}^{*}=1.1 \mathrm{~kg} / \mathrm{cm}^{2}(0.15 \mathrm{MPa})$. Hence, the elasticity modulus $E_{m x}=1.37 \times 10^{3} \mathrm{MPa}$, according to the Mexican code (del Distrito Federal 2004c, section 2.8.5.2), is

$$
E_{m x}=350 f_{m c y}^{\prime}
$$

where $E_{m x}=$ elasticity modulus under sustained loads.

The yield criterion used is Mohr Coulomb; the remaining mechanical properties are shown in Eq. (18): 


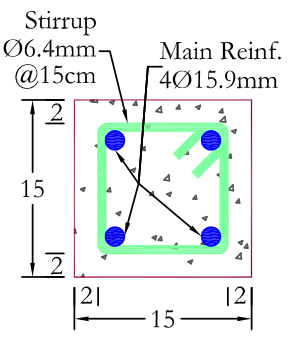

SECTION

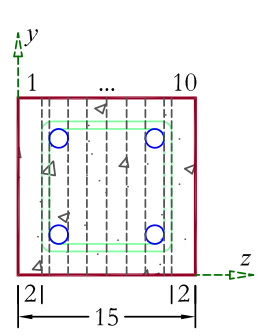

$\frac{\text { 10-LAYERS }}{\text { COLUMN (C-01) }}$
Stirrup

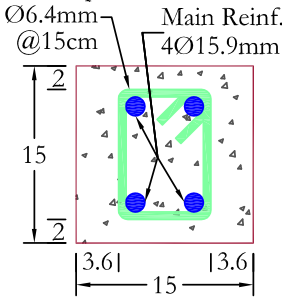

SECTION

BEAM (B-01)

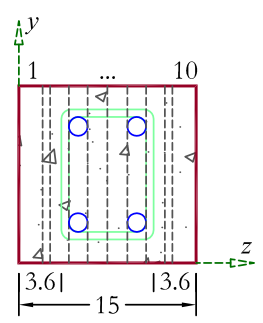

$\frac{\text { 10-LAYERS }}{\text { BEAM (B-01) }}$

(a)
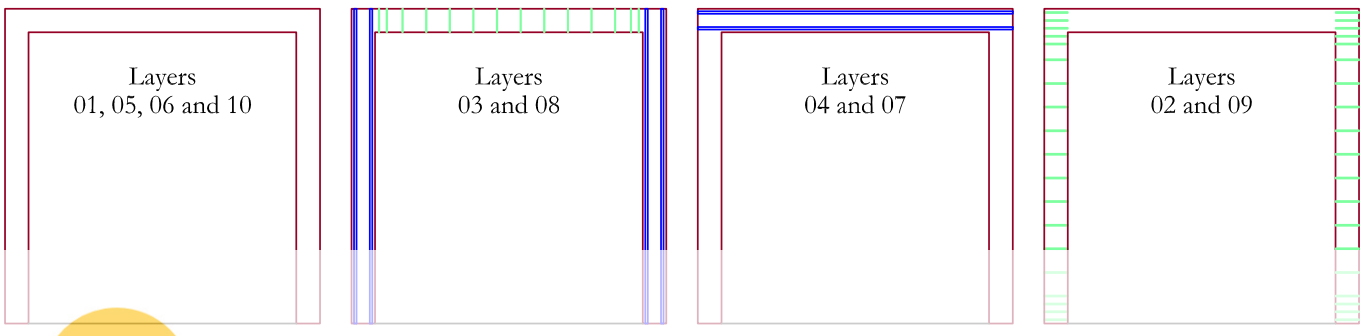

(b)

Fig. 4. Distribution of reinforced fibers and cross section of structural elements for RC frame with masonry in-fills: (a) cross section of structural elements; (b) distribution of steel reinforced fibers in layer

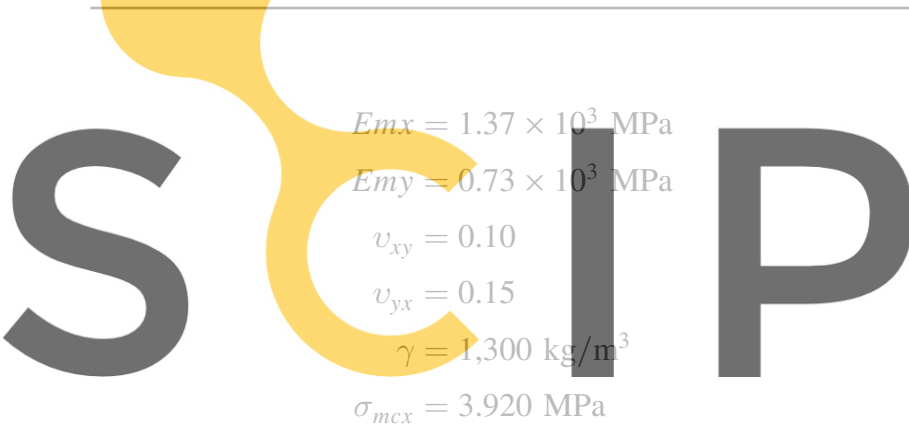

$\begin{aligned} \text { Register for free atchttp } \$ \text { (1) Www.scipedia.com to } & \begin{aligned} \sigma_{m t x} & =200 \mathrm{kPa} \\ \sigma_{m t y} & =65 \mathrm{kPa} \\ G_{c} & =20.0 \mathrm{kPa} \cdot \mathrm{m} \\ G_{t} & =0.2 \mathrm{kPa} \cdot \mathrm{m}\end{aligned}\end{aligned}$

Cross sections of the confining elements are shown in Fig. 4(a). Sections C-01 and B-01 were discretized using 10 layers with different thicknesses because they were adjusted to the location of the steel reinforcement. The general location of the steel reinforcement is shown in Fig. 4(b), where it is observed that Layers 1, 5, 6, and 10 have no steel reinforcement and Layers 3 and 8 contain both the beam stirrup steel reinforcement $(\phi 6.4 \mathrm{~mm})$ and the column's main steel reinforcement $(\phi 15.9 \mathrm{~mm})$. In contrast, Layers 4 and 7 contain only the beam main steel reinforcement and Layers 2 and 9 contain only the column stirrup steel reinforcement. The analysis was performed using two loading stages, the first corresponding to gravity loads obtained using the self-weight of the corresponding material and the second corresponding to a pushover analysis to predict the force-displacement response of the structure.

The force-displacement response in Meli (1979) and that in the present work are compared in Fig. 5(a); Figs. 5(b-d) show the damage state of three different steps $\delta_{1}=0.46, \delta_{2}=1.94$, and $\delta_{3}=7.66 \mathrm{~mm}$. The column on the left shows the damage state of Layer 1 of the confining elements, the column in the center

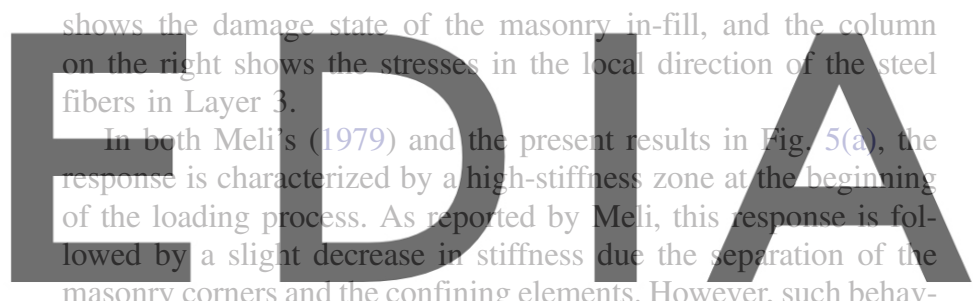

ior was not captured in the present work, leading to a significant

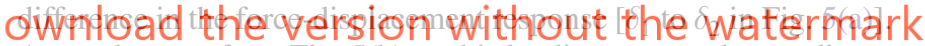
As can be seen from Fig. 5(b), at this loading stage only one diago nal crack is starting to grow. However, beyond the point where a shight loss of stiffness occurs $\left(\delta_{2}\right)$, characterized by the appearance of several diagonal cracks, better agreement between the response in both tests is observed.

\section{One-Story Construction}

A model of a one-story structure with the typical dimensions of a bedroom, referred to as B-OSC, serves to highlight the capabilities of the analysis scheme proposed in this work. Building B-OSC is structured with load-bearing walls and a roofing system based on a solid reinforced concrete slab. It has a window in the rear façade and a window and a door in the front façade. The walls meet the requirements of the Mexican code (del Distrito Federal 2004c) in force for Mexico City:

- Masonry units meet the minimum width necessary to prevent buckling problems in slender walls (del Distrito Federal 2004c, section 5.1.4);

- Reinforced concrete elements that confine the load-bearing masonry walls meet the maximum element separation in plan; in addition, they meet the rates of reinforcing steel necessary for bending and temperature according (del Distrito Federal 2004c, section 5.1.1);

- Openings (doors and windows) are reinforced in the entire perimeter using beams and columns (del Distrito Federal 2004c, section 5.1.3); and 


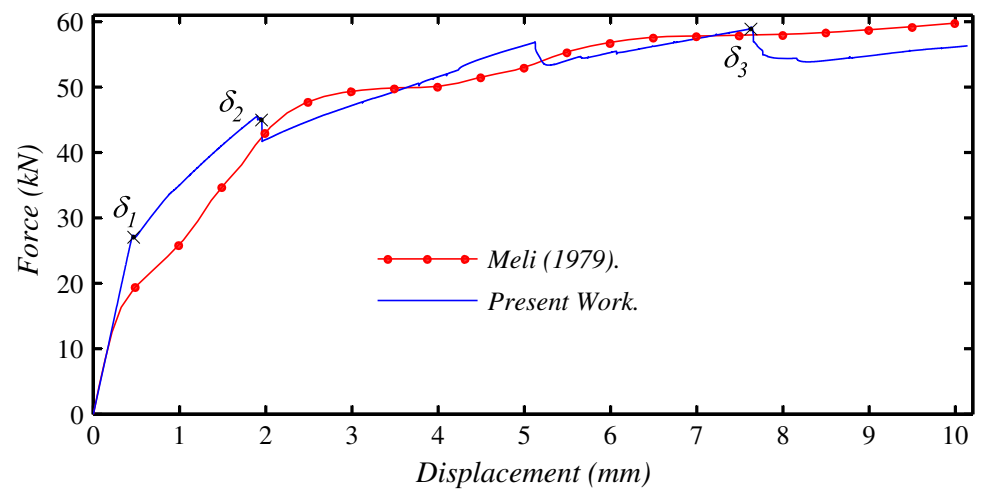

(a)

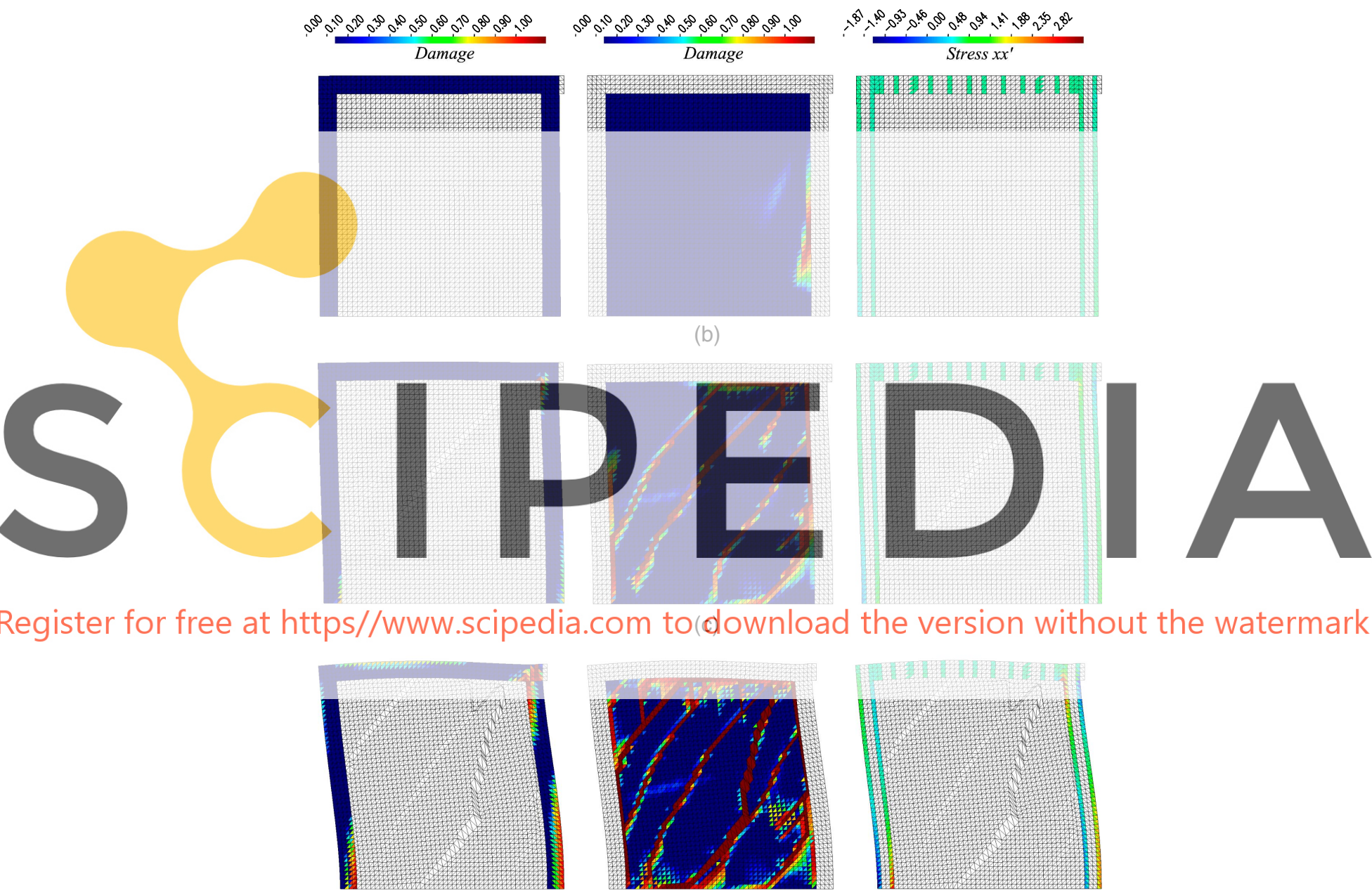

(d)

Fig. 5. Numerical results for RC frame with masonry in-fill: (a) load-displacement comparison; (b) imposed displacement $\delta_{1}=0.46 \mathrm{~mm}$; (c) imposed displacement $\delta_{2}=1.64 \mathrm{~mm}$; (d) imposed displacement $\delta_{3}=7.66 \mathrm{~mm}$

- The thickness of the roof slab meets the requirements for maintaining deflections within stated serviceability limits (del Distrito Federal 2004b, section 3).

\section{Structural Drawings}

The structural drawings for Building B-OSC are shown in Fig. 6. They are as close to real-life construction as possible, especially regarding the distribution of steel reinforcement, with the simplifications only those that a structural engineer would make for easy placement in the field. Typically in structural drawings, the diameters of the reinforcing steel rods are shown in millimeters and correspond to customary units (e.g., 6.4, 9.5, and $1.27 \mathrm{~mm}$ correspond to $1 / 4,3 / 8$, and $1 / 2$ in., respectively). This practice is followed in this section.

\section{Structural Elements}

Brief descriptions of the RC structural elements in Building B-OSC are given in the following subsections.

Masonry In-Fill. The masonry in-fills were discretized using an arrangement of 12 layers whose thicknesses are detailed in Fig. 7. 

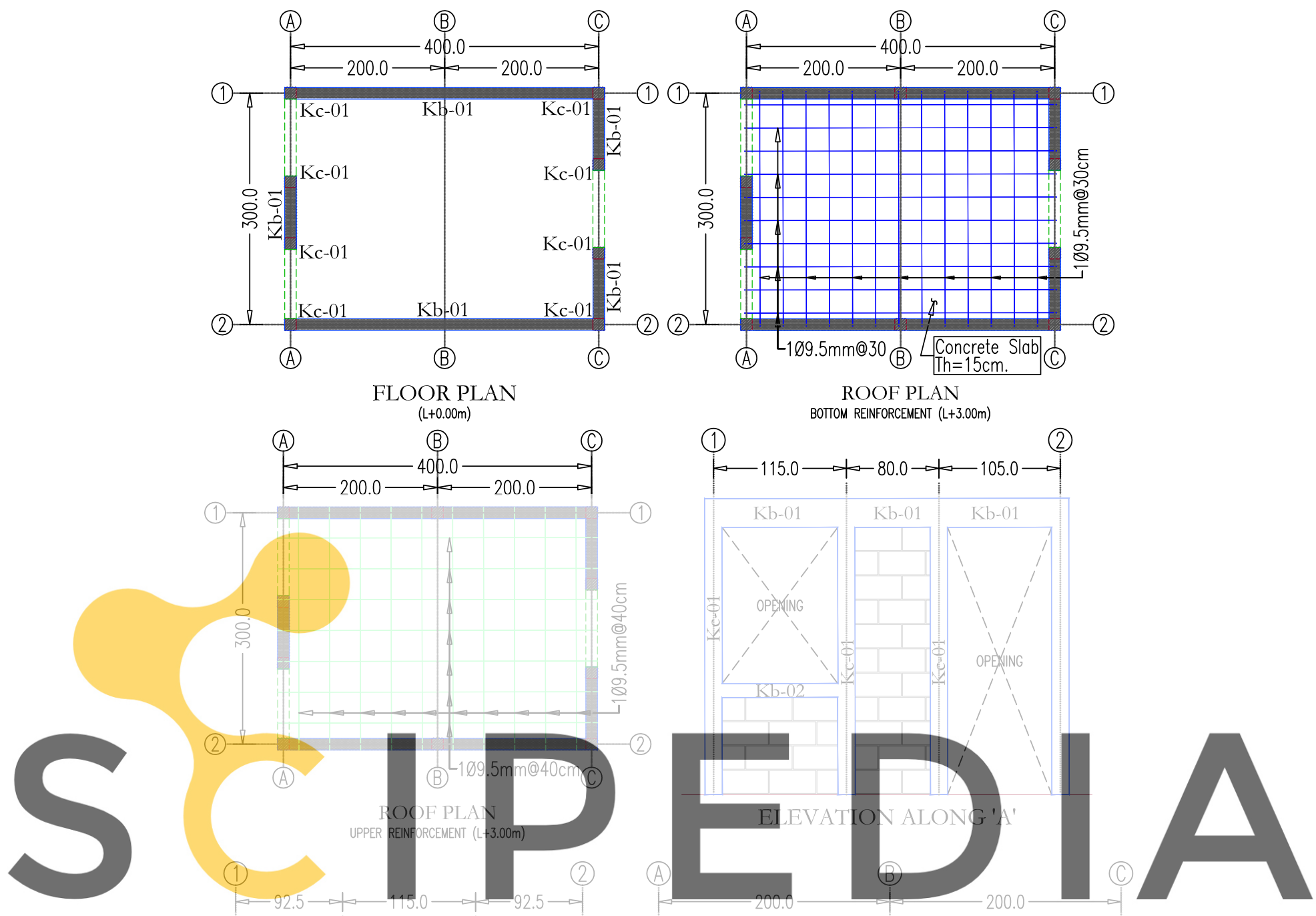

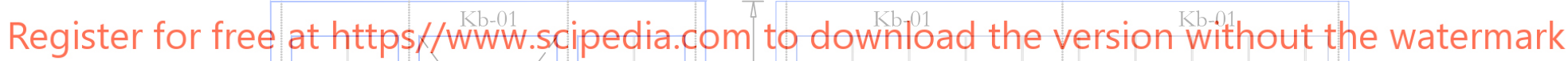

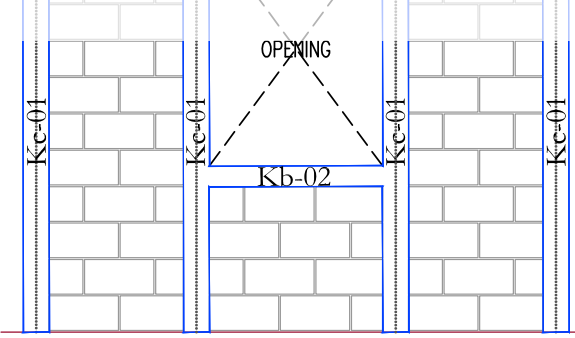

ELEVATION ALONG 'C'

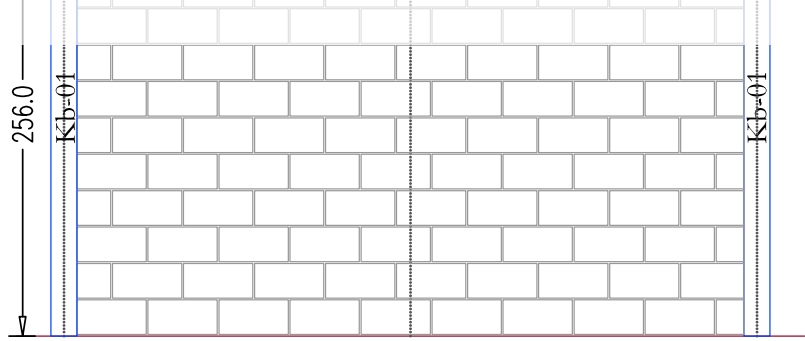

ELEVATION ALONG '1' and '2'

Fig. 6. Structural drawings for one-story construction (centimeter)

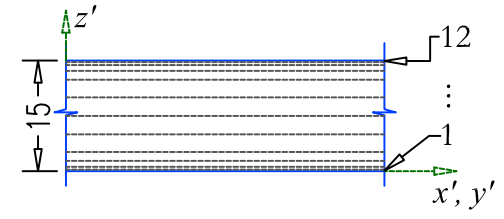

(a)

\begin{tabular}{cccccc}
1 & 2 & 3 & 4 & 5 & 6 \\
\hline 2.0 & 4.0 & 8.0 & 12.0 & 24.0 & 25.0 \\
7 & 8 & 9 & 10 & 11 & 12 \\
\hline 25.0 & 24.0 & 12.0 & 8.0 & 4.0 & 2.0
\end{tabular}

(b)

Fig. 7. Masonry in-fill: (a) detailed section (centimeter); (b) layer distribution (millimeter) 


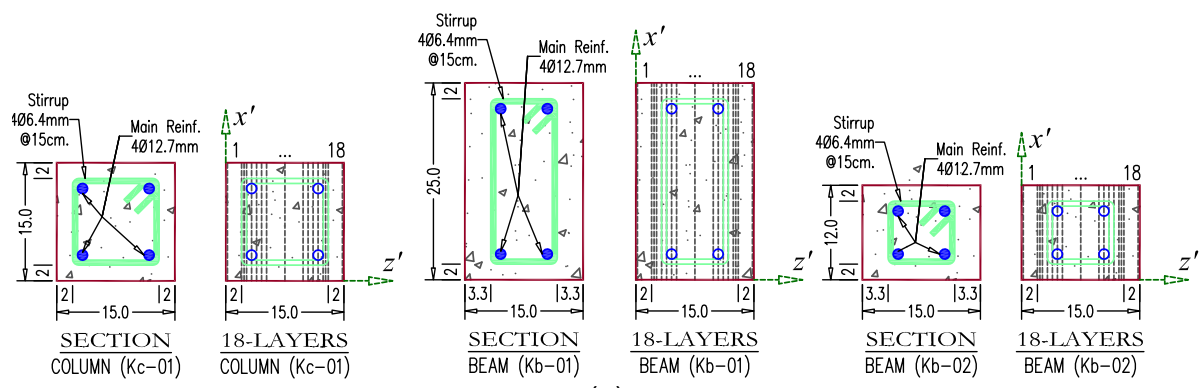

(a)

\begin{tabular}{ccccccccc}
1 & 2 & 3 & 4 & 5 & 6 & 7 & 8 & 9 \\
\hline 2.0 & 18.0 & 3.20 & 3.20 & 6.35 & 6.35 & 6.35 & 6.35 & 23.20 \\
10 & 11 & 12 & 13 & 14 & 15 & 16 & 17 & 18 \\
\hline 23.20 & 6.35 & 6.35 & 6.35 & 6.35 & 3.20 & 3.20 & 18.0 & 2.0
\end{tabular}

(b)

Fig. 8. Columns and beams: (a) detailed section (centimeter); (b) layer distribution (millimeter)

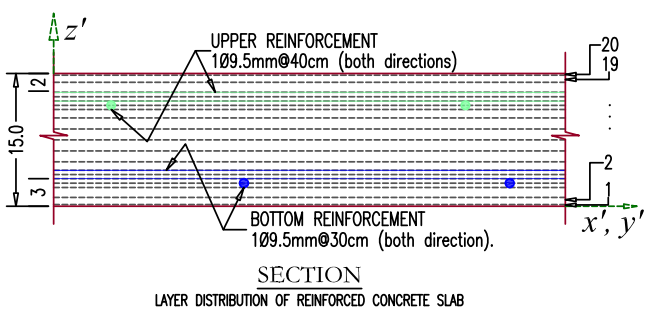

(a)

\begin{tabular}{cccccccccc}
1 & 2 & 3 & 4 & 5 & 6 & 7 & 8 & 9 & 10 \\
\hline 2.0 & 8.0 & 11.2 & 5.0 & 5.0 & 4.75 & 4.75 & 9.5 & 12.4 & 12.4 \\
11 & 12 & 13 & 14 & 15 & 16 & 17 & 18 & 19 & 20 \\
\hline 12.4 & 12.4 & 9.5 & 4.75 & 4.75 & 5.0 & 5.0 & 11.2 & 8.0 & 2.0
\end{tabular}

(b)

Fig. 9. Slab: (a) detailed section (centimeter); (b) layer distribution (millimeter)

Columns. One type of cross section is used for columns [Fig. 8(a)], referred to as Kc-01 and endowed with a main steel reinforcement of four $\phi 12.7-\mathrm{mm}$ (1/2-in.) rods. The secondary steel reinforcement is formed by $\phi 6.4-\mathrm{mm}(1 / 4-i n$.$) steel rods separated by distances of$ $15 \mathrm{~cm}$. Cross Section Kc-01 was discretized using an arrangement of 18 layers whose thicknesses are also given in Fig. 8(b).

Beams. Two sections of beams were used. The first one, Kb-01, was used in the regular walls (at the union of the beam and the concrete slab); the second one, $\mathrm{Kb}-02$, was used in the lower walls (forming the window opening).

Fig. 8(a) shows the SRP and layer distribution of Kb-01 and $\mathrm{Kb}-02$. The basic difference between the two is their height. In both, the main steel reinforcement (four $\phi 12.7-\mathrm{mm}$ rods) and the secondary steel reinforcement ( $\phi 6.4-\mathrm{mm}$ rods at 15 -cm separation) were the same, and the thickness was discretized using an arrangement of 18 layers [Fig. 8(b)]. Also, in both cases the beam sections had a coating for the transverse steel of $33 \mathrm{~mm}$ (left and right side) and $20 \mathrm{~mm}$ in the upper and lower parts; this is usually done in the field as an adjustment to prevent longitudinal steel overlaps.

Slabs. Although the simple materials that make up the concrete slab were fixed to exhibit linear behavior, the slab was discretized using a pattern of 20 layers for a total thickness of $15 \mathrm{~cm}$ [Fig. 9(b)]. Layer distribution can be seen in Fig. 9(a), where the steel reinforcement in both beds and in both orthogonal directions is also shown. The diameters of the steel reinforcement rods were both $\phi 9.5 \mathrm{~mm}$ (3/8 in.). The figure also shows the different separation distances between the steel rods-for the lower bed, $30 \mathrm{~cm}$; for the upper bed, $40 \mathrm{~cm}$.

\section{Simple Material Properties}

Only three simple materials were needed to perform the analysis of Model B-OSC: steel, concrete, and masonry. The mechanical and constitutive properties of these materials are detailed next.

Steel. The yield criterion used to describe the behavior of steel was von Mises; the other mechanical properties are described in Eq. (19):

$$
\begin{aligned}
E & =2.1 \times 10^{5} \mathrm{MPa} \\
v & =0.00 \\
\gamma & =7845 \mathrm{~kg} / \mathrm{m}^{3} \\
\sigma_{c} & =420 \mathrm{MPa} \\
\sigma_{t} & =420 \mathrm{MPa} \\
G_{c} & =2.0 \mathrm{MPa} \cdot \mathrm{m} \\
G_{t} & =2.0 \mathrm{MPa} \cdot \mathrm{m}
\end{aligned}
$$

Concrete. The concrete compressive strength was assumed equal to $f_{c}^{\prime}=250 \mathrm{~kg} / \mathrm{cm}^{2}\left(24.53 \times 10^{6} \mathrm{~N} / \mathrm{m}^{2}\right)$. The elasticity modulus was evaluated according to section 1.5.1.4 of the Mexican code (del Distrito Federal 2004c):

$$
E=4400 \sqrt{f_{c y}^{\prime}}
$$

Here units are in MPa and the yield criterion is Mohr Coulomb. All other mechanical properties are shown in Eq. (21): 

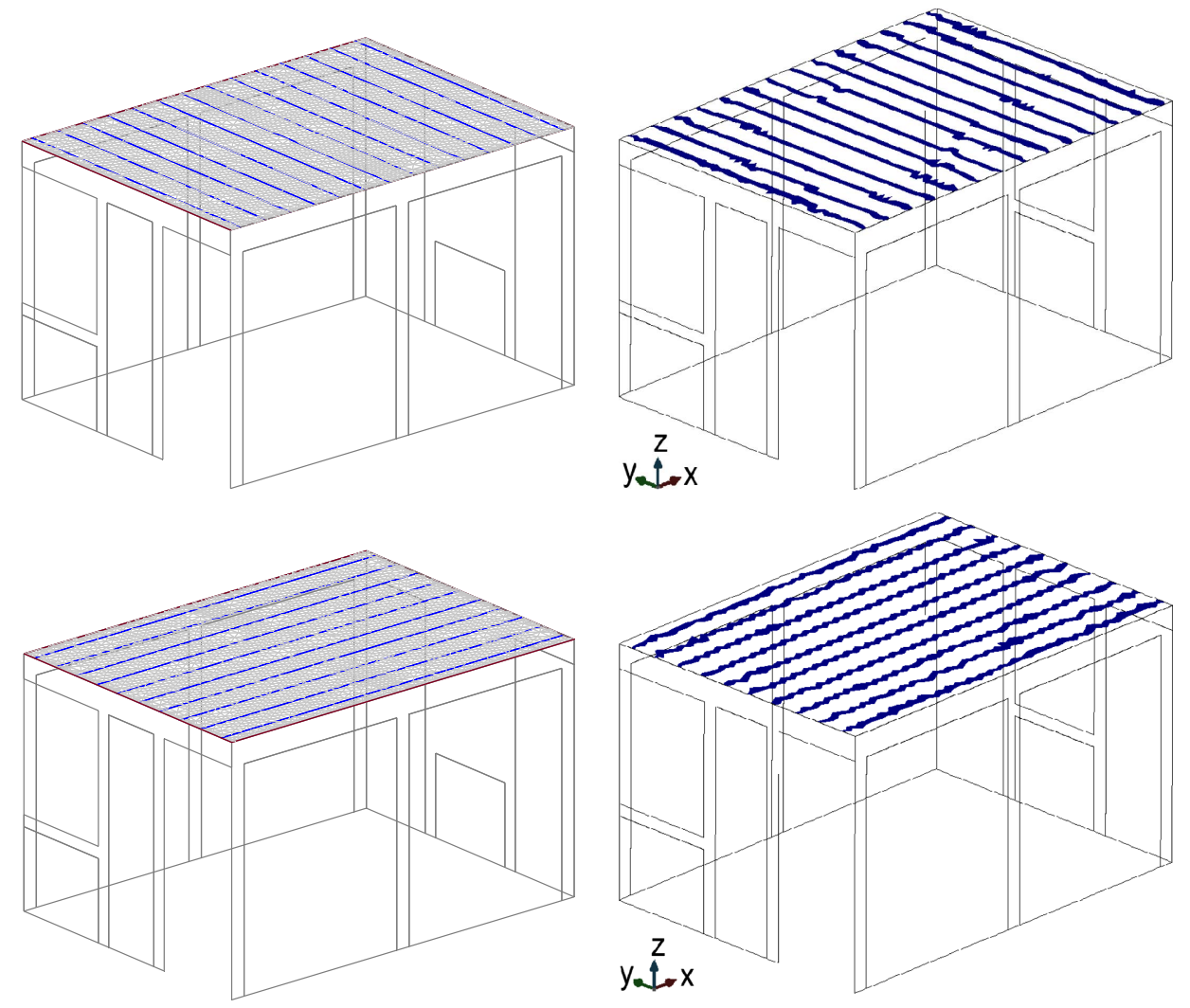

Fig. 10. Fiber reinforcement on slab

$$
\begin{aligned}
E & =2.5 \times 10^{4} \mathrm{MPa} \quad v=0.20 \quad \gamma=2,500 \mathrm{~kg} / \mathrm{m}^{3} \\
\sigma_{c} & =25.0 \mathrm{MPa} \quad \sigma_{t}=3.50 \mathrm{MPa} \\
G_{c} & =50.0 \mathrm{kPa} \cdot \mathrm{m} \quad G_{t}=5.0 \mathrm{kPa} \cdot \mathrm{m}
\end{aligned}
$$

Masonry. The mechanical properties of masonry were obtained assuming that the simple compressive strength $\left(f_{m c y}\right)$ of the combination of masonry units and mortar was equal to $f_{m}^{*}=$ $120 \mathrm{~kg} / \mathrm{cm}^{2}$ whereas the maximum shear strength was equal to

\begin{tabular}{|c|c|c|c|}
\hline MATERIAL & $\begin{array}{c}\text { THICKNESS } \\
(\mathrm{cm})\end{array}$ & $\begin{array}{l}\text { WEIGHT } \\
\left(\mathrm{kg} / \mathrm{m}^{3}\right)\end{array}$ & $\begin{array}{l}\text { WEIGHT } \\
\left(\mathrm{kg} / \mathrm{m}^{2}\right)\end{array}$ \\
\hline MASONRY WALL & 12.0 & 1500 & 180 \\
\hline INNER PLASTER & 1.2 & 1500 & 18 \\
\hline OUTER PLASTER & 2.0 & 2100 & 42 \\
\hline \multirow{2}{*}{ DEAD LOAD* } & \multicolumn{2}{|c|}{ DUE TO CONCRETE } & -- \\
\hline & \multicolumn{2}{|c|}{ DUE TO MORTAR } & 20 \\
\hline
\end{tabular}
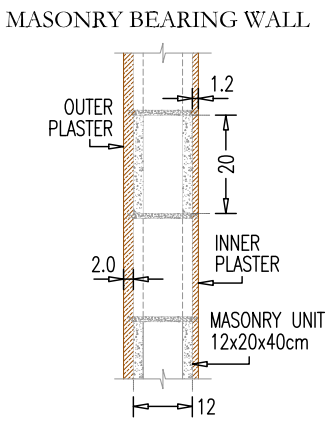

$v_{m}^{*}=3.5 \mathrm{~kg} / \mathrm{cm}^{2}$. Once these parameters were defined accordinging to the Mexican Code (del Distrito Federal 2004c), it was possible to define the elasticity and shear modulus:

$$
\begin{aligned}
E_{m} & =E_{1}=E_{2}=600 f_{m}^{*}=7.06 \times 10^{3} \mathrm{MPa} \\
G_{x y} & =0.4 E_{m}=2.825 \times 10^{3} \mathrm{MPa}
\end{aligned}
$$

\begin{tabular}{|c|c|c|c|}
\hline MATERIAL & $\begin{array}{l}\text { THICKNESS } \\
(\mathrm{cm})\end{array}$ & $\begin{array}{l}\text { WEIGHT } \\
\left(\mathrm{kg} / \mathrm{m}^{3}\right)\end{array}$ & $\begin{array}{l}\text { WEIGHT } \\
\left(\mathrm{kg} / \mathrm{m}^{2}\right)\end{array}$ \\
\hline BRICK PAVING & 2.0 & 1500 & 30 \\
\hline MORTAR & 1.50 & 2100 & 31.5 \\
\hline AGGREGATE & 5.0 & 1200 & 60 \\
\hline CONRETE SLAB & 15.0 & 2400 & 360 \\
\hline \multirow{2}{*}{ DEAD LOAD* } & \multicolumn{2}{|c|}{ DUE TO CONCRETE } & 20 \\
\hline & \multicolumn{2}{|c|}{ DUE TO MORTAR } & 20 \\
\hline
\end{tabular}

The yield criterion used was Mohr Coulomb. The remaining mechanical and constitutive properties are described in Eq. (23):

ROOFING SYSTEM

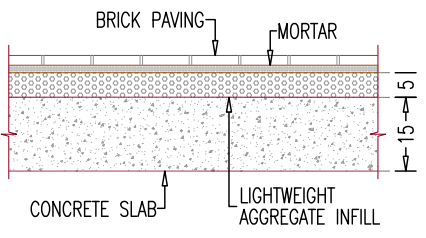

Fig. 11. Dead loads: masonry bearing walls and roofing system 


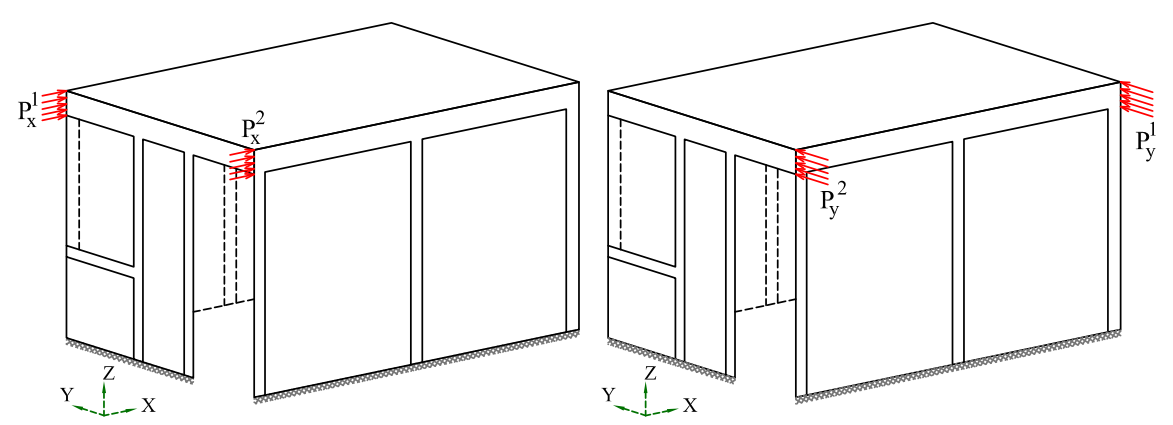

Fig. 12. Application loads in pushover analysis
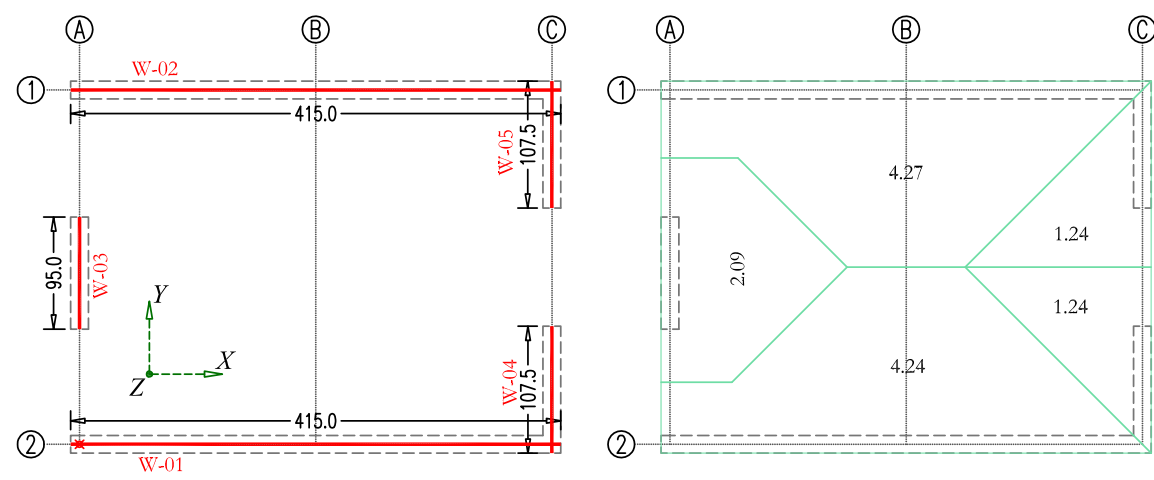

Fig. 13. Bearing walls and tributary areas (centimeter)

$$
\begin{aligned}
\gamma & =1,500 \mathrm{~kg} / \mathrm{m}^{3} \quad f_{m c x}=5.15 \mathrm{MPa} \quad f_{m c y}=12.00 \mathrm{MPa} \\
f_{m t x} & =350 \mathrm{kPa} \quad f_{m t y}=600 \mathrm{kPa} \quad G_{c}=20.0 \mathrm{kPa} \cdot \mathrm{m} \\
G_{t} & =0.5 \mathrm{kPa} \cdot \mathrm{m}
\end{aligned}
$$

\section{Composite Material Generation}

Because the methodology employed to obtain the volume fraction for the composite materials was described previously, only the case of one SCM, the concrete slab (Fig. 10), is considered here. The FE of the SCM was plotted, as were the contour of the slab, the steel reinforcement, and the contour of the remaining SCM for reference. Only the bottom steel reinforcement is shown in the figure. At the right of the figure, the corresponding FE with ${ }^{f} k>0$ is shown.

\section{Boundary Conditions}

The numerical analysis was performed using three loading phases. In none of these phases were the loading factors that are normally included in building code regulations used; neither was the security factor for design purposes. The analysis was purposely performed in this way so that the results obtained using a design code could be properly compared with the results obtained using the scheme proposed in this work.

Fixed Displacements. In all loading phases, the basement of the structure was set to remain rigidly fixed, so neither displacements nor rotations were allowed.

First-Stage Loading Condition: Dead Loading. Dead loading combines the weight of the elements with a structural purpose and the weight of the elements used only to fulfill architectural requirements. At the left of Fig. 11 are the structural and architectural elements belonging to the masonry walls and a table of thicknesses and weights of the wall components. At the right is a sketch of the roofing system and a table of thicknesses and weights of the roofing components. Pursuant to Article 197 of the Mexican code (del Distrito Federal 1993), $40 \mathrm{~kg} / \mathrm{m}^{2}$ was added to the total weight because of the presence of concrete and mortar, $D_{L} \approx$ $525.0 \mathrm{~kg} / \mathrm{m}^{2}$.

Second-Stage Loading Condition: Live Loading. Live loads are temporary and of short duration (compared with permanent loads).

Table 1. Masonry Wall Stiffness and Shear Strength

\begin{tabular}{lcc}
\hline Wall & Stiffness $(\mathrm{kN} / \mathrm{m})$ & Shear strength $(\mathrm{kN})$ \\
\hline W-01 & $474,002.72$ & 221.53 \\
W-02 & $474,002.72$ & 221.53 \\
W-03 & $14,787.67$ & 52.77 \\
W-04 & $20,907.57$ & 57.65 \\
W-05 & $20,907.57$ & 57.65 \\
\hline
\end{tabular}

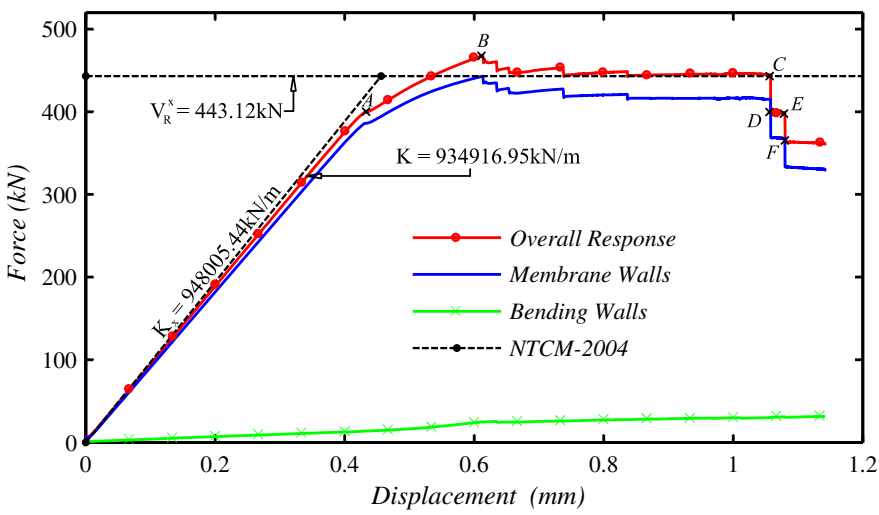

Fig. 14. Displacement-force response of Model B-OSC in $X$-direction 
They conform to regulations - in this work the Reglamento de construcciones para el Distrito Federal (del Distrito Federal 1993), in which Chapter V, Article 199.V.g, calls for a uniform load of $100 \mathrm{~kg} / \mathrm{m}^{2}$ for the roof in residential homes where the slope of the roof is less than or equal to $5 \%$.

Third-Stage Loading Condition: Pushover. The third loading stage involves a pushover applied separately in both orthogonal directions $X$ and $Y$. Hence, for both directions the displacements shown in Fig. 12 were imposed. The purpose of this loading step is to predict the force-displacement response of the structure.

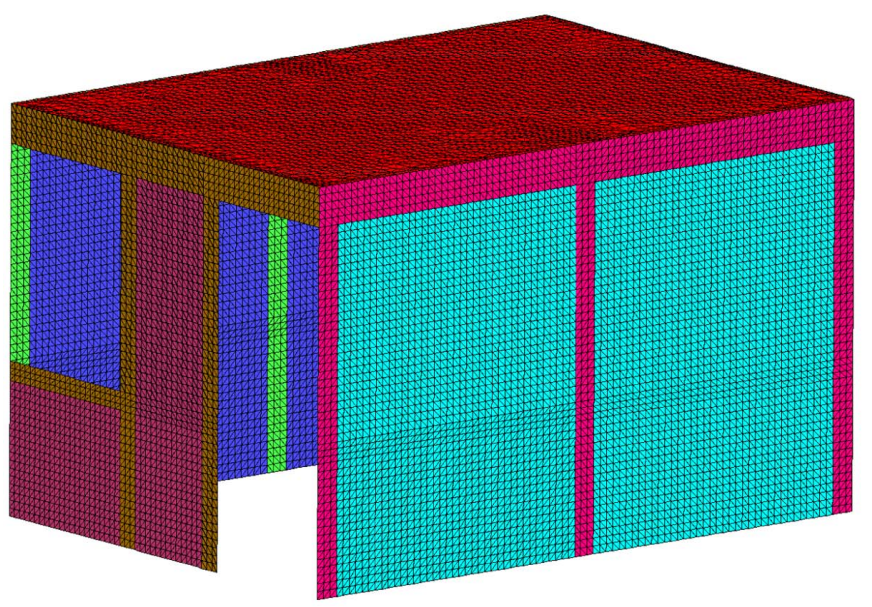

(a)

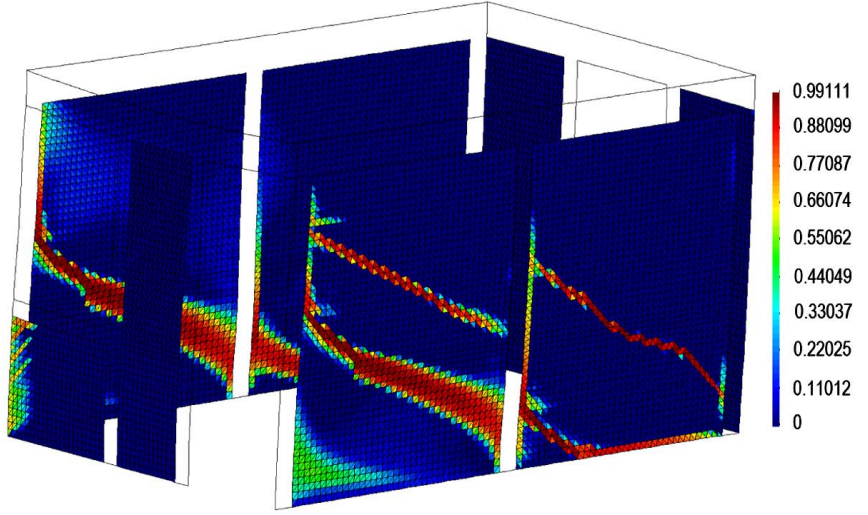

(c)

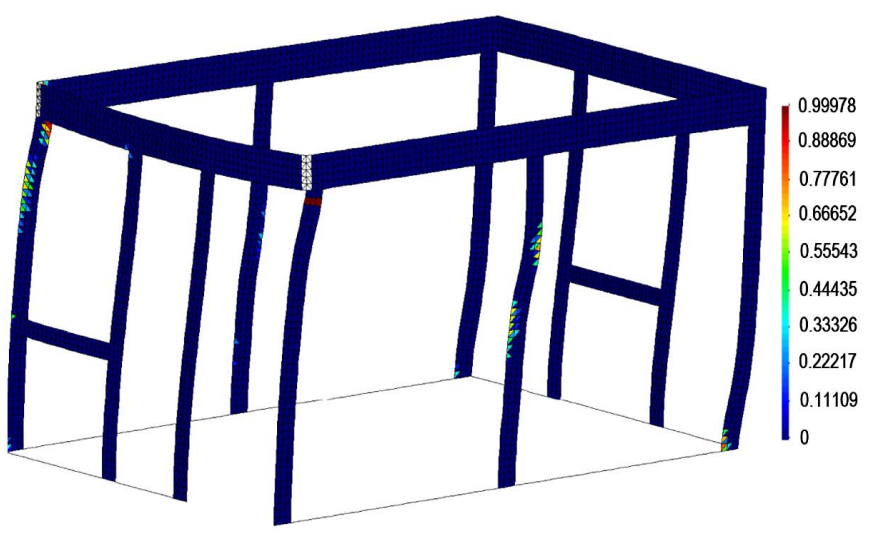

(e)
Reference Solution: Mexican Building Code

The Normas técnicas complementarias para diseño y construcciones de estructuras de mamposteria (del Distrito Federal 2004c) defines the requirements for a masonry structure bearing different loads throughout its service life. It also defines the total stiffness of the structure required to verify its seismic behavior and its total shear strength. These two parameters were used to validate the response provided by the numerical simulation.

At the left of Fig. 13 is an enumeration for masonry walls and their total length. Such an enumeration is important because most

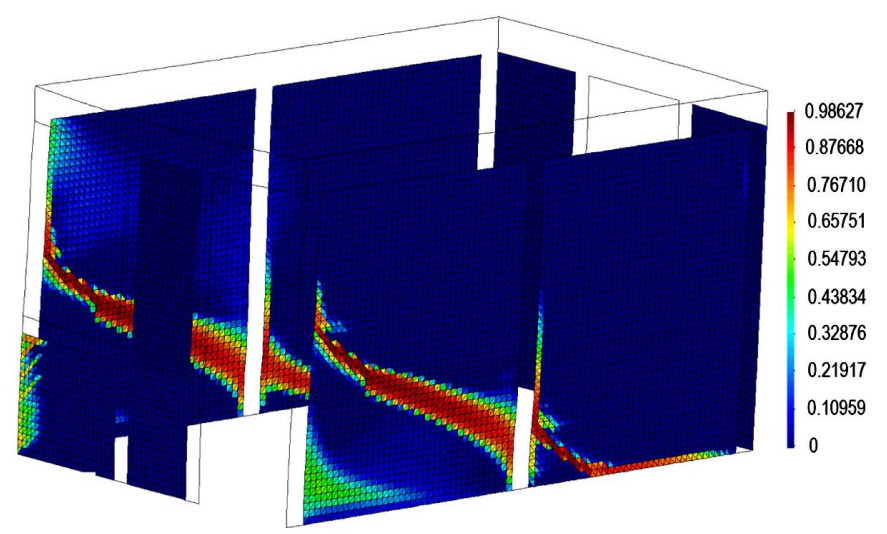

(b)

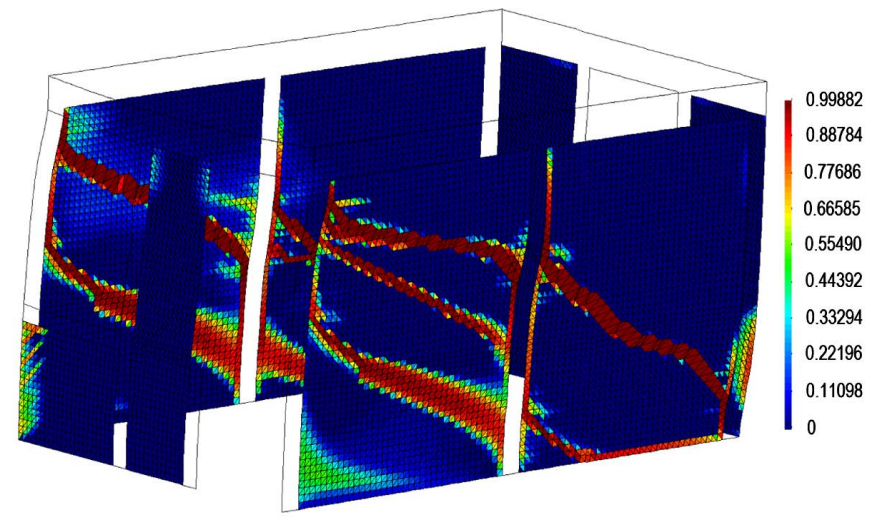

(d)

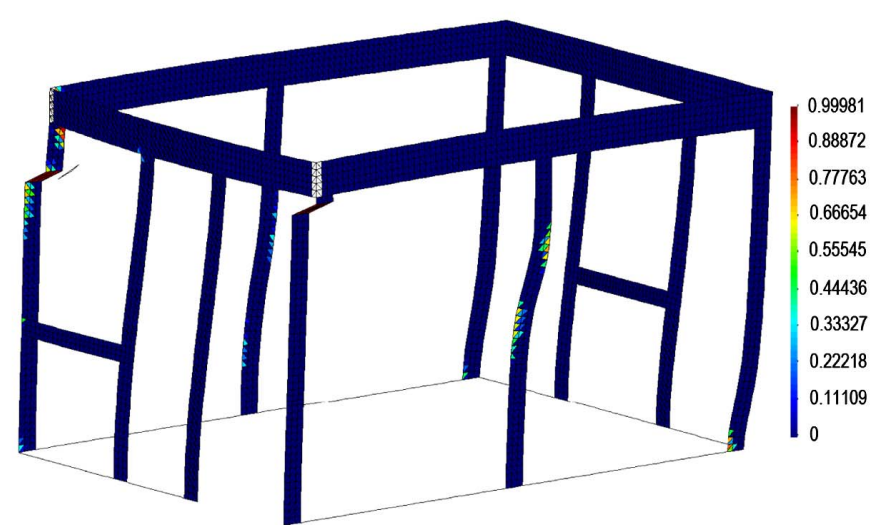

(f)

Fig. 15. Front isometric view of damage evolution in masonry walls in $X$-direction: (a) undeformed mesh; (b) displacement $=0.580 \mathrm{~mm}$; (c) displacement $=0.630 \mathrm{~mm}$; (d) displacement $=1.057 \mathrm{~mm}$; (e) displacement $=1.060 \mathrm{~mm}$; (f) displacement $=1.060 \mathrm{~mm}$ 
of the results presented next refer to it. At the right of the figure is the tributary load of the individual masonry walls, which numbered five in total.

For analysis purposes regarding the Mexican code (del Distrito Federal 2004c), the short walls that form part of the window were not considered nor was the stiffness because of the reinforced concrete confining elements. Also, according to the detailed analysis in del Distrito Federal (2004c), the walls perpendicular to the analysis direction (in plan view) were neglected, so in such cases stiffness and shear strength were equal to 0 . To evaluate the total stiffness and shear strength of the structure in the $X$-direction, then, only Walls W-01 and W-02 were considered (Fig. 13) and for the $Y$-direction only Walls W-03, W-04, and W-05 were considered.

Table 1 lists the stiffnesses and shear strengths of the masonry walls evaluated according to the Mexican code (del Distrito Federal 2004c). From it the total stiffness of the structure in both orthogonal directions can be inferred:

$$
\mathbf{K}_{x}=948,005.44 \mathrm{kN} / \mathrm{m} ; \quad \mathbf{K}_{y}=56,602.81 \mathrm{kN} / \mathrm{m}
$$

Also from Table 1 it is possible to obtain the total shear strength of the structure in both orthogonal directions:

$$
\mathbf{V}_{R}^{x}=443.12 \mathrm{kN} ; \quad \mathbf{V}_{R}^{y}=168.07 \mathrm{kN}
$$

The values shown in Eqs. (24) and (25) were used to validate the obtained results.

\section{Comparison of Results: $X$-Direction Analysis}

The response of the structure when the displacement was applied in the $X$-direction is described using the graph in Fig. 14, which shows the combined response of Walls W-03, W-04, and W-05. These walls are referred to as shell walls because their ability to restrict displacements in the $X$-direction arises from their flexural stiffness. On the other hand, because of the combined response of Walls $\mathrm{W}-01$ and $\mathrm{W}-02$, these walls are referred as membrane walls because their ability to avoid displacements in $X$-direction arises from their membrane stiffness acting as cantilever beams with height equal to the corresponding length of the masonry wall. Finally, the figure shows the combined response of both membrane and shell walls.

It can be observed in Fig. 14 that there is good agreement between the stiffness evaluated using the Mexican code (del Distrito Federal 2004c) and the total stiffness of the masonry walls evaluated using the proposed scheme, even though neither concrete nor steel stiffness is considered by the former. Also showing reasonably good agreement is total shear strength, which in the Mexican code (del Distrito Federal 2004c) is defined as the point where nonlinear processes begin. The graph in Fig. 14 also confirms the low stiffness of the bending walls and indicates that they can be neglected for analysis and design purposes. In order to properly describe the displacement-force response graph, it is divided into six segments:

- Segment $\overline{\mathbf{O A}}$, where the elastic response occurs;

- Segment $\overline{\mathbf{A B}}$, where the first crack appears, reaching the maximum shear strength of the entire structure in the $X$-direction at point B;

- Segment $\overline{\mathbf{B C}}$, corresponding to the entire capability of the masonry walls expended to support lateral forces; beyond Point $\mathbf{C}$, high discontinuities are expected because the resistance due to lateral forces is provided only by the confining elements;

- Segment $\overline{\mathbf{C D}}$, a sudden lost of stiffness due to the rupture of the confining elements at one of the points where the loads are applied;

- Segment $\overline{\mathbf{D E}}$, which can be described as a small amount of lateral force that the structure can support until the next rupture of a confining element; and

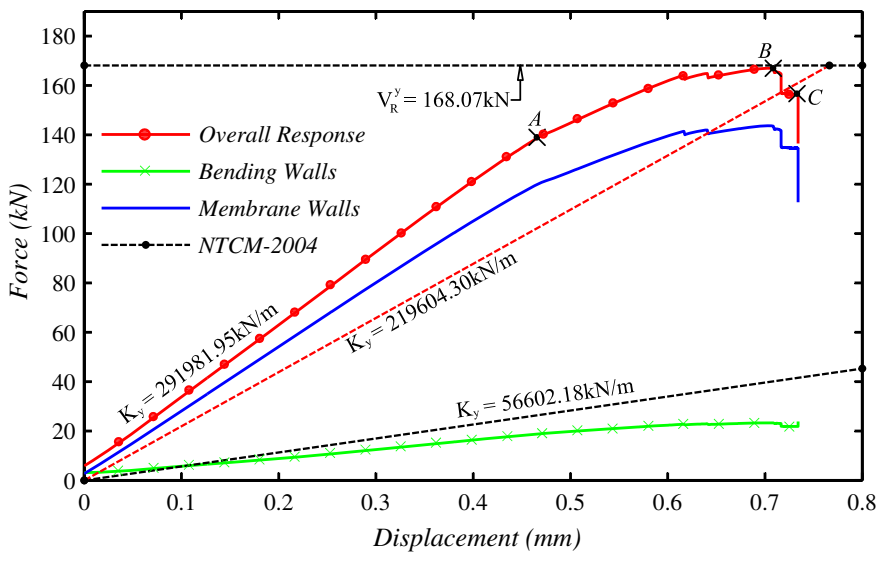

Fig. 16. Displacement-force response of Model B-OSC in $Y$-direction

Table 2. Shortened Masonry Wall Stiffness and Shear Strength

\begin{tabular}{lc}
\hline Wall & Stiffness $(\mathrm{kN} / \mathrm{m})$ \\
\hline W-03 & $58,733.22$ \\
W-04 & $80,335.54$ \\
W-05 & $80,335.54$ \\
\hline
\end{tabular}

- Segment $\overline{\mathbf{E F}}$, which is the sudden rupture of other confining elements at the point where the displacement is imposed.

Fig. 15 is a set of images of the ongoing deformation from a frontal perspective, mostly showing the principal façade and Wall $\mathrm{W}-01$, although Wall W-02 is also visible (in all images, the deformation is amplified 200 times). Fig. 15(a) shows the undeformed mesh; Figs. 15(b-d) show the crack patterns in the masonry in-fill for three loading steps; and Figs. 15(e and f) show the damage in the confining $\mathrm{RC}$ elements.

\section{Comparison of Results: $Y$-Direction Analysis}

From the analysis in the $Y$-direction, the first inference is the low stiffness compared with that in the $X$-direction. The displacementforce graph in Fig. 16 leads to the same inference regarding bending and masonry walls as for the $X$ direction analysis. In this case, the bending walls are $\mathrm{W}-01$ and $\mathrm{W}-02$, whereas the membrane walls are $\mathrm{W}-03, \mathrm{~W}-04$, and $\mathrm{W}-05$. The figure shows the separate contribution of the walls and overall response, total stiffness, and total shear strength obtained according to the Mexican code (del Distrito Federal 2004c).

The first observation from the displacement-force response is the evident mismatch between the stiffness evaluated using the Mexican code (del Distrito Federal 2004c) and that obtained using the proposed scheme. Apart from the omission of the steel and concrete, such a mismatch results from the contribution of the short walls (the walls forming the windows openings) because they act as stiffeners, shortening the total height of the adjacent walls. Table 2 better points out the stiffener effect of short walls. There stiffness is evaluated for the shortened walls; that is, their height is reduced in such a way that it is considered from the top of the short walls to the slab. If such consideration is given, the reported stiffness is $\mathbf{K}_{y}=219404.31 \mathrm{kN} / \mathrm{m}$ (Table 2), which leads to a more precise prediction of total stiffness.

The displacement-force graph (Fig. 16) is divided into segments to provide a proper description. The segments are described as follows:

- Segment $\overline{\mathbf{O A}}$, where the elastic response occurs, reporting a total stiffness $\mathbf{K}=291,981.95 \mathrm{kN} / \mathrm{m}$, which is 5.15 times 
the stiffness evaluated using the Mexican code (del Distrito Federal 2004c); thus it can be said that short walls should be included to obtain a more accurate evaluation of stiffness;

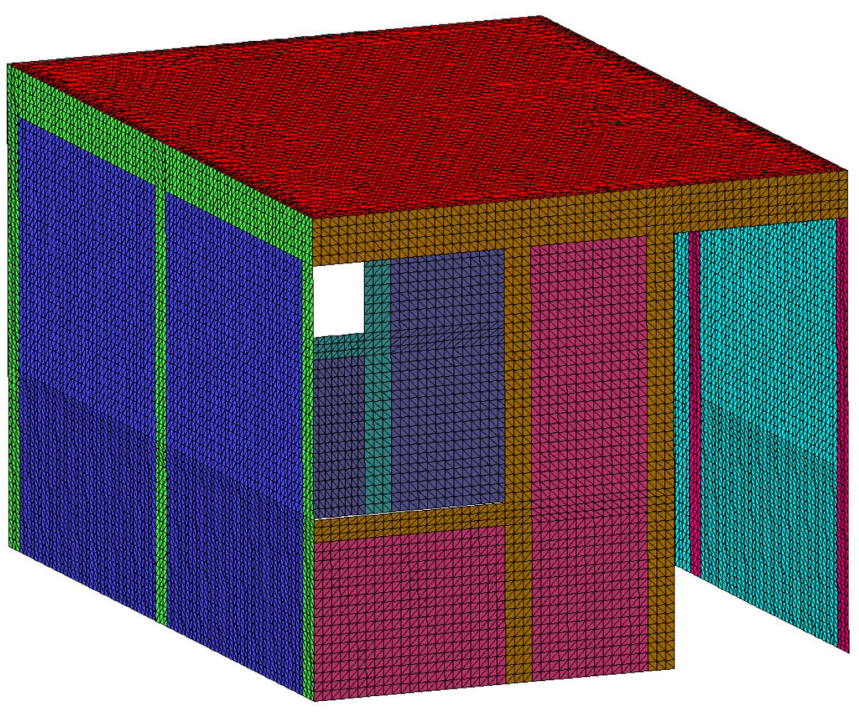

(a)

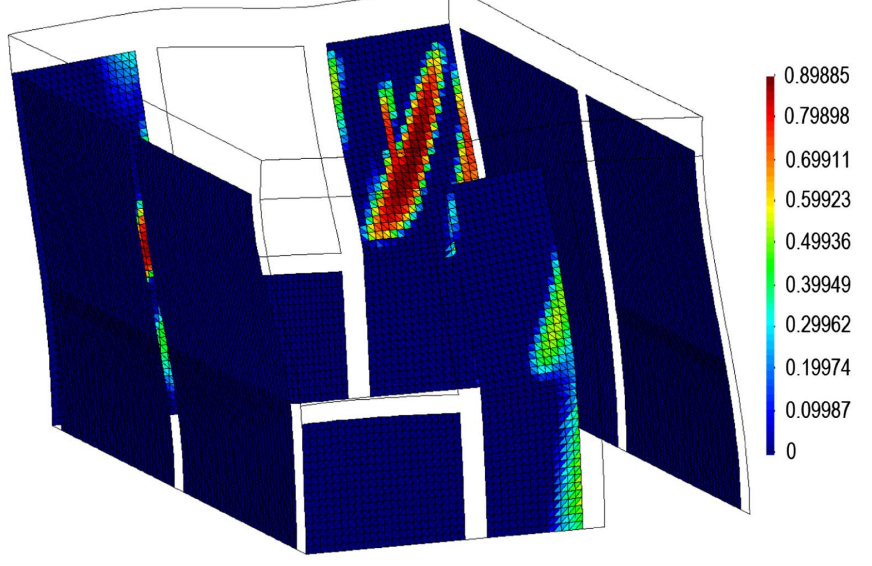

(c)

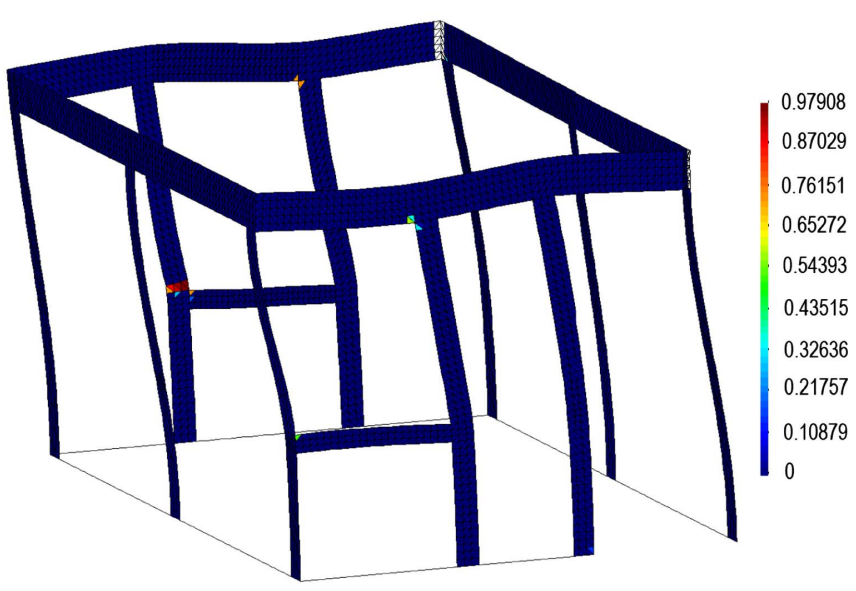

(e)
- Segment $\overline{\mathbf{A B}}$, which corresponds to the propagation of cracks, reaching the maximum shear strength of the structure at Point B; there is good agreement between the shear strength obtained using the Mexican code (del Distrito Federal 2004c) and

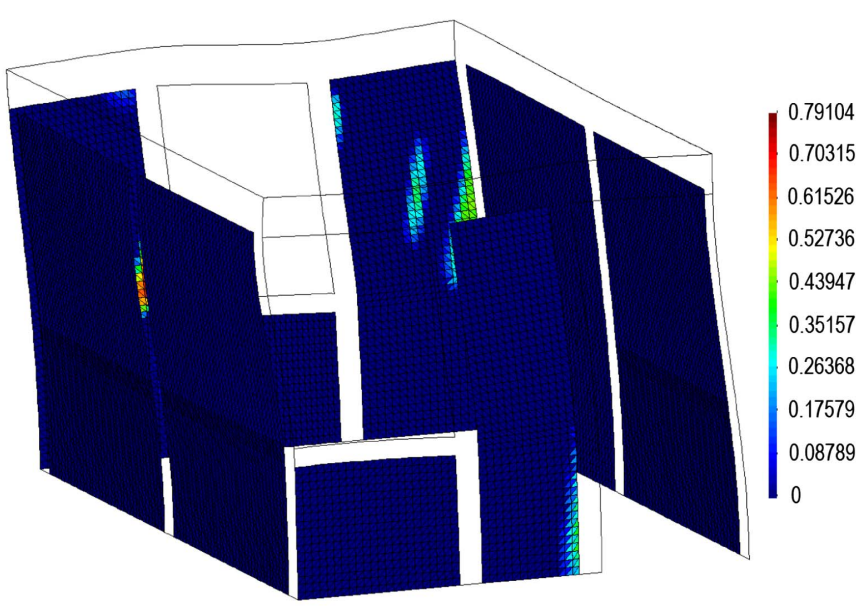

(b)

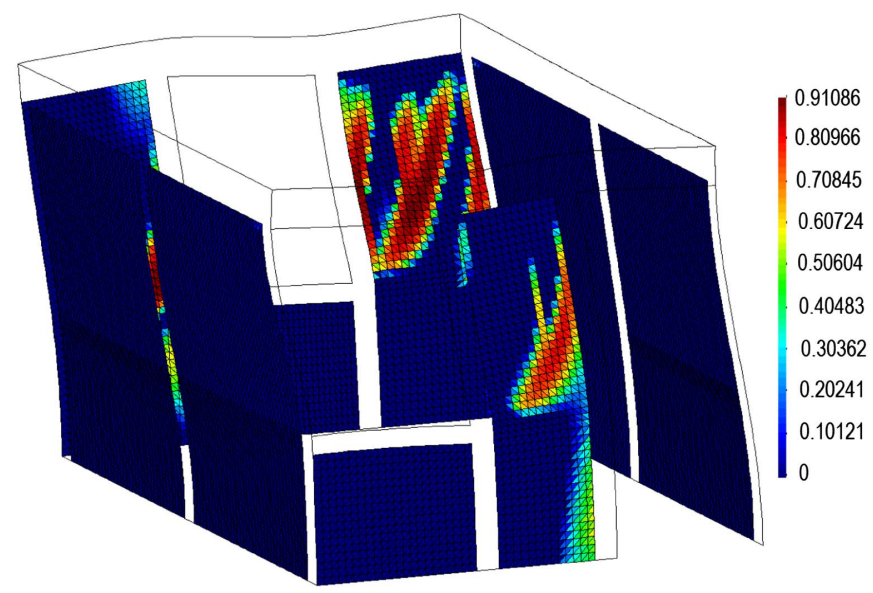

(d)

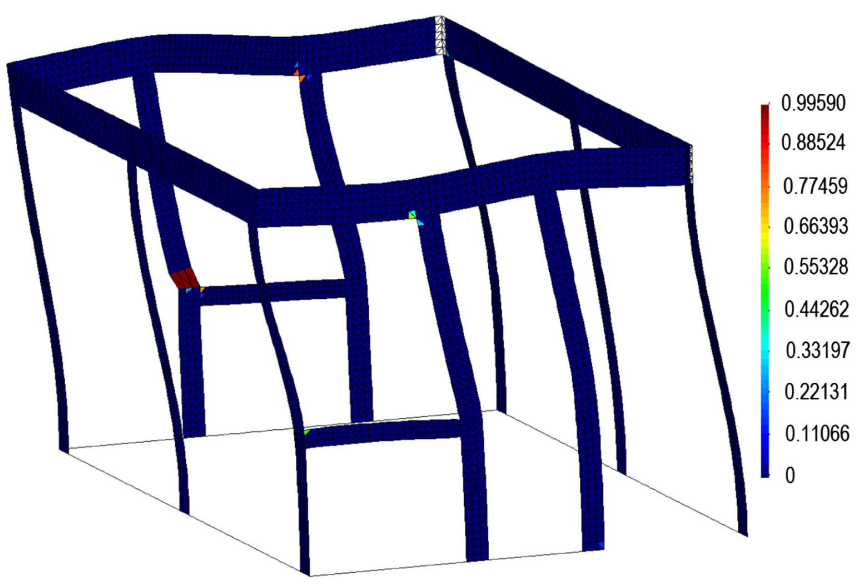

(f)

Fig. 17. Front isometric view of damage evolution in masonry walls in $Y$-direction: (a) undeformed mesh; (b) displacement $=0.4726$ mm; (c) displacement $=0.6166 \mathrm{~mm}$; (d) displacement $=0.7109 \mathrm{~mm}$; (e) displacement $=0.7119 \mathrm{~mm}$; (f) displacement $=0.7339 \mathrm{~mm}$ 
the maximum shear strength obtained from the proposed scheme; and

- Segment $\overline{\mathbf{B C}}$, where the resistance of the structure starts to decrease until it reaches Point $\mathrm{C}$, beyond which there is a sudden loss of stiffness because of the rupture at the bottom corner of the confining elements in the walls of the rear façade.

The images in Fig. 17 describe the damage evolution [the deformation is amplified 500 times except in Fig. 17(a), the reference mesh]. Fig. 17(b) shows a loading step (imposed displacement equal to $0.4726 \mathrm{~mm}$ ) where the nonlinear process starts. As can be seen, slight damage starts in Wall W-03 at the union of Confining Column Kc-01 and the brickwork. The crack propagates vertically along Wall W-03 [Figs. 17(c and d)] until it reaches the horizontal confining element at the top (Beam Kb-01); it then propagates diagonally until it reaches Confining Element $\mathrm{Kb}-02$. Figs. 17(e and $\mathrm{f}$ ) show slight damage in the confining element at the corners of the window openings. The damage at the bottom of Wall W-03 (from the bottom of the window opening to the foundation of the wall) is almost zero because of the small tensional stress in this area; the same is true for Walls W-04 and W-05.

\section{Conclusions}

This work analyzed large masonry structures using a proposed methodology implemented in the context of the finite-element method and compared with the methodology employed in Mexican national building code. Good results were obtained.

The starting point of this work was the use of a 3-node 2D triangular shell element with one Gauss point (Escudero 2015) combined with state-of-the-art mixture theories for composite materials (Escudero et al. 2016; Martinez et al. 2008; Rastellini et al. 2008). This combination made it possible to analyze RC as a composite whose components could be modeled with nonlinear constitutive equations. Although the proposed methodology was applied only to masonry structures, it can easily be extended to frame structures with or without masonry in-fills.

The following conclusions regarding this work can be drawn: - The use of a macromodeling technique combined with plain finite elements proved effective; there was good agreement between the modeled structures and the results obtained using the Mexican code (del Distrito Federal 1993, 2004a, b, c, d);

- It was proved that there are significant differences in the stiffness of masonry walls when the planes of the walls are perpendicular (bending) and parallel (membrane) to the direction of the acting force; this effect is taken into account in most construction codes, assuming that greater damage occurs on membrane walls and neglecting, for design purposes, bending walls; this coincides with the results obtained in this work; and

- In the cases studied, the stiffener effect was observed, produced by short masonry walls (formed at the windows openings) that change the stiffness entirely and consequently change the structural behavior of the adjacent masonry walls.

In order to reproduce the steel reinforcement pattern of real-life construction, a computational tool was developed that fulfilled three principal requirements:

- It must reproduce a more realistic reinforcement pattern;

- It must provide a mechanical process to generate the volume participation of the different components of the composite; and

- It must be capable of handling large-mesh information.

Finally, because of the size of the models considered in this work, it was necessary to adopt a programming strategy that reduced execution time and computational resource (RAM) expenditures. The strategy described in this paper proved effective in this regard.

\section{Acknowledgments}

This work has been supported by the European Commission, under the Marie Curie program (IRSES agreement 612607, TCAINMAND project), by the European Research Council (Advanced Grant ERC-2012-AdG 320815 COMP-DES-MAT Advanced Tools for Computational Design of Engineering Materials), by the European Community (Grant NMP-2009-2.5-1 246067 Multiscale Reinforcement of Semi-Crystalline Thermoplastic Sheets and Honeycombs), by the Spanish Ministerio de Economia y Competividad (Project MAT2014-60647-R Multi-Scale and Multi-Objective Optimization of Composite Laminate Structures), and by the the Mexican government through a grant provided by CONACyT to complete Ph.D. studies. This support is gratefully acknowledged.

\section{References}

Allman, D. (1984). "A compatible triangular element including vertex rotations for plane elasticity analyses.” Comput. Struct., 19(1-2), 1-8.

Barney, B., et al. (2010). "Introduction to parallel computing." (https:// computing.1lnl.gov/tutorials/openMP/\#Introduction〉 (May 8, 2017).

Batoz, J.-L. (1982). "An explicit formulation for an efficient triangular platebending element.” Int. J. Numer. Methods Eng., 18(7), 1077-1089.

Batoz, J.-L., Bathe, K.-J., and Ho, L.-W. (1980). "A study of three-node triangular plate bending elements." Int. J. Numer. Methods Eng., 15(12), 1771-1812.

Bazant, Z. P., and Pijaudier-Cabot, G. (1989). "Measurement of characteristic length of nonlocal continuum." J. Eng. Mech., 10.1061/(ASCE) 0733-9399(1989)115:4(755), 755-767.

Bergan, P., and Felippa, C. (1985). "A triangular membrane element with rotational degree of freedom." Comput. Methods Appl. Mech. Eng., $50(1), 25-69$.

Brzev, S. (2007). Earthquake-resistant confined masonry construction, National Information Center of Earthquake Engineering, Indian Institute of Technology Kanpur, Kanpur, India.

Chaboche, J. (1988a). "Continuum damage mechanics. I: Damage growth, crack initiation, and crack growth." J. Appl. Mech., 55(1), 65-72.

Chaboche, J. (1988b). "Continuum damage mechanics. I: General concepts." J. Appl. Mech., 55(1), 59-64.

CIMNE (International Center for Numerical Methods in Engineering). (2014). "PLCd-Non-linear thermomechanic finite element code." $\langle$ http://www.cimne.com/PLCd〉 (May 8, 2017).

CIMNE (International Center for Numerical Methods in Engineering). (2015). "GiD_Adaptive and user-friendly pre and postprocessor for numerical simulations in science and engineering." $\langle$ http://www .gidhome.com/> (May 8, 2017).

del Distrito Federal, G. (1993). Reglamento de Construcciones Gobierno del Distrito Federal, México City.

del Distrito Federal, G. (2004a). Normas Técnicas Complementarias para Diseño por Sismo, México City.

del Distrito Federal, G. (2004b). Normas Técnicas Complementarias para Diseño y Construcciones de Estructuras de Concreto, México City.

del Distrito Federal, G. (2004c). Normas Técnicas Complementarias para Diseño y Construcciones de Estructuras de Mampostería, México City.

del Distrito Federal, G. (2004d). Normas Técnicas Complementarias sobre Criterios y Acciones para el Diseño Estructural de las Edificaciones, México City.

Eijo, A. (2014). "Finite element modelling of delamination in advanced composite beams and plates using one- and two-dimensional finite elements based on the refined zigzag theory." Ph.D. dissertation, Escola Tècnica Superior D’Enginyers de Camins, Canals I Ports, Universitat Politècnica de Catalunya, Barcelona, Spain.

Escudero, C. (2015). "Numerical calculation model for the global analysis of concrete structures with masonry walls." Ph.D. thesis, Escola Tècnica 
Superior D'Enginyers de Camins, Canals I Ports, Universitat Politècnica de Catalunya, Barcelona, Spain.

Escudero, C., Oller, S., Martinez, X., and Barbat, A. H. (2016). "A laminated structural finite element for the behavior of large nonlinear reinforced concrete structures." Finite Elem. Anal. Des., 119, 78-94.

Esteva, L. (1961). Comportamiento de muros de mampostería sujetos a carga vertical, Instituto de Ingenieria, Universidad Nacional Autonoma de Mexico, Mexico City.

Esteva, L. (1963). Estimaciones de daños probables producidos por temblores en edificios, Instituto de Ingenieria, Universidad Nacional Autonoma de Mexico, Mexico City.

Esteva, L. (1966). "Behaviour under alternating loads of masonry diaphragms framed by reinforced concrete members." Proc., Int. Symp. on the Effects of Repeated Loadings of Materials and Structures, RILEM, México City, 1-36.

Faria, R., Oliver, J., and Cervera, M. (1998). "A strain-based plastic viscous-damage model for massive concrete structures." Int. J. Solids Struct., 35(14), 1533-1558.

Felippa, C. (2003). "A study of optimal membrane triangles with drilling freedom." Comput. Methods Appl. Mech. Eng., 192(16), 2125-2168.

Fundación ICA. (1999). Edificaciones de mampostería para vivienda, México City.

Hernández, O. (1975). Recomendaciones para el diseño y construcción de estructuras de mampostería, Instituto de Ingeniería, Universidad Nacional Autónoma de México, México City.

Hillerborg, A., Modéer, M., and Petersson, P.-E. (1976). “Analysis of crack formation and crack growth in concrete by means of fracture mechanics and finite elements." Cem. Concr. Res., 6(6), 773-781.

Hughes, T., and Brezzi, F. (1989). "On drilling degrees of freedom." Comput. Methods Appl. Mech. Eng., 72(1), 105-121.

Jason, L., Huerta, A., Pijaudier-Cabot, G., and Ghavamian, S. (2006). "An elastic plastic damage formulation for concrete: Application to elementary tests and comparison with an isotropic damage model." Comput. Methods Appl. Mech. Eng., 195(52), 7077-7092.

Ju, J. (1989). "On energy-based coupled elastoplastic damage theories: Constitutive modeling and computational aspects." Int. J. Solids Struct., 25(7), 803-833.

Khosravi, P., Ganesan, R., and Sedaghati, R. (2007). "Corotational nonlinear analysis of thin plates and shells using a new shell element." Int. J. Numer. Methods Eng., 69(4), 859-885.

Kojić, M., and Bathe, K.-J. (2005). Inelastic analysis of solids and structures, Springer, Berlin.

Lemaitre, J. (1985). "Coupled elasto-plasticity and damage constitutive equations." Comput. Methods Appl. Mech. Eng., 51(1), 31-49.

Lourenço, P. (1996). "Computational strategies for masonry structures." Ph.D. dissertation, Delft Univ., Delft, Netherlands.

Lourenço, P. B., Milani, G., Tralli, A., and Zucchini, A. (2007). "Analysis of masonry structures: Review of and recent trends in homogenization techniques." Can. J. Civ. Eng., 34(11), 1443-1457.

Lubliner, J., Oliver, J., Oller, S., and Oñate, E. (1989). "A plastic-damage model for concrete." Int. J. Solids Struct., 25(3), 299-326.

Madinaveitia, M. (1971). Ensayes de muros de mampostería con cargas excéntricas, Instituto de Ingenieria, Universidad Nacional Autonoma de Mexico, Mexico City.

Madinaveitia, M., and Rodríguez, G. (1970). Resistencia a carga vertical de muros fabricados con materiales usuales en el distrito federal, Instituto de Ingenieria, Universidad Nacional Autonoma de Mexico, Mexico City.

Martinez, X. (2008). "Micro-mechanical simulation of composite materials using the serial/parallel mixing theory." Ph.D. thesis, Escola Tècnica Superior D'Enginyers de Camins, Canals I Ports, Universitat Politècnica de Catalunya, Barcelona.

Martinez, X., Oller, S., Barbu, L. G., Barbat, A., and De Jesus, A. (2015). "Analysis of ultra low cycle fatigue problems with the Barcelona plastic damage model and a new isotropic hardening law." Int. J. Fatigue, 73, $132-142$.

Martinez, X., Oller, S., Rastellini, F., and Barbat, A. (2008). "A numerical procedure simulating RC structures reinforced with FRP using the serial/parallel mixing theory." Comput. Struct., 86(15), 1604-1618.

Mazars, J., and Pijaudier-Cabot, G. (1989). "Continuum damage theoryApplication to concrete.” J. Eng. Mech., 10.1061/(ASCE)0733-9399 (1989)115:2(345), 345-365.

Meli, R. (1979). Comportamiento sísmico de muros de mampostería, 2nd Ed., Instituto de Ingenieria, Universidad Nacional Autonoma de México, México City.

Meli, R., and Alcocer, S. M. (2004). "Implementation of structural earthquake-disaster mitigation programs in developing countries." Nat. Hazards Rev., 10.1061/(ASCE)1527-6988(2004)5:1(29), 29-39.

Meli, R., and Hernández, O. (1971). Propiedades de piezas para mampostería producidas en el distrito federal, Instituto de Ingeniería, Universidad Nacional Autonoma de México, México City.

Meli, R., and Hernández, O. (1975). Efectos de hundimientos diferenciales en construcciones a base de muros de mampostería, Instituto de Ingenieria, Universidad Nacional Autonoma de Mexico, México City.

Meli, R., and Reyes, A. (1971). Propiedades mecánicas de la mampostería, Instituto de Ingenieria, Universidad Nacional Autonoma de Mexico, México City.

Meli, R., and Salgado, G. (1969). Comportamiento de muros de mampostería sujetos a carga lateral, Instituto de Ingenieria, Universidad Nacional Autonoma de Mexico, México City.

Meli, R., Zeevart, W., and Esteva, L. (1968). Comportamiento de muros de mampostería hueca ante carga lateral alternada, Instituto de Ingenieria, Universidad Nacional Autonoma de Mexico, México City.

Oliver, J., Cervera, M., Oller, S., and Lubliner, J. (1990). "Isotropic damage models and smeared crack analysis of concrete." Proc., 2nd Int. Conf. on Computer Aided Analysis and Design of Concrete Structures, Pineridge Press, Swansea, U.K., 945-958.

Oller, S. (1998). "Un modelo de daño continuo para materiales friccionales." Ph.D. thesis, Escola Tècnica Superior D'Enginyers de Camins, Canals I Ports, Universitat Politècnica de Catalunya, Barcelona, Spain.

Oller, S., Car, E., and Lubliner, J. (2003). "Definition of a general implicit orthotropic yield criterion." Comput. Methods Appl. Mech. Eng., 192(7), 895-912.

Oller, S., Oñate, E., Miquel Canet, J., and Botello, S. (1993). "A finite element model for analysis of multiphase composite materials." ICCM/9, 3, 94-103.

Oñate, E., Oller, S., Botello, S., and Canet, J. M. (1991). Métodos avanzados de cálculo de estructuras de materiales compuestos, Centro Internacional de Métodos Numéricos en Ingeniera, Barcelona, Spain.

Ortiz, M., and Popov, E. P. (1982). "Plain concrete as a composite material." Mech. Mater., 1(2), 139-150.

Paredes, J. A. (2013). "Modelización numérica del comportamiento constitutivo del daño local y global y su correlación con la evolución de las frecuencias naturales en estructuras de hormigón reforzado." Ph.D. dissertation, Escola Tècnica Superior D'Enginyers de Camins, Canals I Ports, Universitat Politècnica de Catalunya, Barcelona.

Paredes, J. A., Barbat, A. H., and Oller, S. (2011). "A compression-tension concrete damage model, applied to a wind turbine reinforced concrete tower." Eng. Struct., 33(12), 3559-3569.

Pelà, L. (2009). "Continuum damage model for nonlinear analysis of masonry structures." Ph.D. thesis, Università degli studi di Ferrara, Ferrara, Italy.

Rastellini, F., Oller, S., Salomón, O., and Oñate, E. (2008). "Composite materials non-linear modelling for long fibre-reinforced laminates: Continuum basis, computational aspects and validations." Comput. Struct., 86(9), 879-896.

Rastellini, F. G. (2006). "Modelación numérica de la no-linealidad constitutiva de laminados compuestos." Ph.D. thesis, Escola Tècnica Superior D'Enginyers de Camins, Canals I Ports, Universitat Politècnica de Catalunya, Barcelona.

Rots, J. G. (1997). Structural masonry: An experimental/numerical basis for practical design rules, A.A. Balkema, Rotterdam, Netherlands.

Rots, J. G., and De Borst, R. (1987). "Analysis of mixed-mode fracture in concrete." J. Eng. Mech., 10.1061/(ASCE)0733-9399(1987)113: 11(1739), 1739-1758.

Simo, J., and Hughes, T. (1998). Computational inelasticity, Vol. 7, Springer, New York. 
Simo, J., and Ju, J. (1987). "Strain- and stress-based continuum damage models. II: Computational aspects." Int. J. Solids Struct., 23(7), 841-869.

Simo, J., and Ju, J. (1989). "Strain- and stress-based continuum damage models. I: Formulation." Math. Comput. Model., 12(3), 378.

Tao, X., and Phillips, D. V. (2005). "A simplified isotropic damage model for concrete under bi-axial stress states." Cem. Concr. Compos., 27(6), 716-726.
Truesdell, C., and Toupin, R. (1960). The classical field theories, Springer, New York.

Turkstra, C. (1970). Resistencia de muros de mampostería ante cargas verticales excéntricas, Instituto de Ingenieria, Universidad Nacional Autonoma de Mexico, Mexico City.

Vargas-Félix, M., and Botello-Rionda, S. (2012). "FEMT, an open source library and tools for solving large systems of equations in parallel." Centro de Investigacion en Matemáticas, A.C., Guanajuato, Mexico. 